(Revised manuscript)

\title{
Iminophosphorane-phosphines: Versatile ligands for homogeneous catalysis
}

\author{
Joaquín García-Álvarez, Sergio E. García-Garrido and Victorio Cadierno*
}

Laboratorio de Compuestos Organometálicos y Catálisis (Unidad Asociada al CSIC), Departamento de Química Orgánica e Inorgánica, Instituto Universitario de Química Organometálica "Enrique Moles”, Universidad de Oviedo, Julián Clavería 8, 33006 Oviedo, Spain

*Corresponding author. E-mail address: vcm@uniovi.es (V. Cadierno) 


\begin{abstract}
Iminophosphoranes $\mathrm{R}_{3} \mathrm{P}=\mathrm{NR}$ are nitrogen analogues of phosphorus ylides that can coordinate transition metals using the lone pair on the nitrogen atom. The integration of supplementary donor sites into the iminophosphorane backbone yields polydentate ligands of increasing interest in both coordination chemistry and catalysis. Herein, a comprehensive account of the applications of mixed ligands featuring both a phosphine and an iminophosphorane moiety in homogeneous catalysis is presented. Among others, metalcatalyzed hydrogenation and transfer hydrogenation reactions, C-C cross-couplings, olefin oligomerization and cyclopropanation processes, allylic alkylation and oxidation reactions, Meyer-Schuster rearrangements and cycloisomerization processes are discussed.
\end{abstract}

Keywords: Iminophosphoranes; Functionalized phosphines; Polydentate ligands; Hemilabile ligands; Homogeneous catalysis

\title{
Contents
}

1. Introduction

2. Hydrogenation and transfer hydrogenation reactions

3. Cross-coupling reactions

4. Oligomerization and cyclopropanation of olefins

5. Other catalytic transformations

6. Conclusions 


\section{Introduction}

Iminophosphoranes, also referred to as phosphoranimines, phosphinimines or phosphazenes, are organic compounds of general composition $\mathrm{R}_{3} \mathrm{P}=\mathrm{NR}$. Although the discovery of these nitrogen analogues of phosphorus ylides dates back to 1919 [1], the chemistry of iminophosphoranes has only been explored in depth during the last three decades. However, the maturity reached is such that these compounds find now a wide range of relevant applications [2], which include their use as versatile intermediates in organic synthesis (e.g. aza-Wittig reaction) [3], as "superbases" [4], or as building blocks for P-Nbackbone polymers (e.g. polyphosphazenes) [5]. Several methods of synthesis of iminophosphoranes are known, but the so-called Staudinger and Kirsanov reactions are by far the most general and widely used (Scheme 1) [2]. In both cases a phosphine ( $\left.\mathrm{PR}_{3}\right)$ is used as the starting material, with the Staudinger reaction involving its direct oxidation with an organic azide $[1,6]$, and the Kirsanov one its initial bromination and subsequent treatment of the resulting $\mathrm{P}(\mathrm{V})$ phosphine-dibromide with a primary amine in the presence of a base $[7,8]$.

$$
\begin{aligned}
& \mathrm{R}_{3} \mathrm{P}+\mathrm{RN}_{3} \longrightarrow \mathrm{R}_{3} \mathrm{P}=\mathrm{NR}+\mathrm{N}_{2} \quad \text { (Staudinger reaction) } \\
& \mathrm{R}_{3} \mathrm{P}+\mathrm{Br}_{2} \longrightarrow \mathrm{R}_{3} \mathrm{PBr}_{2} \frac{\mathrm{RNH}_{2} / \text { base }}{-2[\text { baseH]Br }}-\mathrm{R}_{3} \mathrm{P}=\mathrm{NR} \quad \text { (Kirsanov reaction) }
\end{aligned}
$$

Scheme 1. General methods of synthesis of iminophosphoranes.

Iminophosphoranes possess a highly polarized $\mathrm{P}=\mathrm{N}$ bond, and are best described as resonance hybrids of the two extreme canonical forms $\mathbf{A}$ and $\mathbf{B}$ (Figure 1). In addition, they are able to coordinate transition metals via the lone pair of the approximately $\mathrm{sp}^{2}$-hybridized nitrogen atom to give stable complexes $\mathbf{C}$ (Figure 1) [9]. However, we must note that the intrinsic coordinating ability of iminophosphoranes, which are predominantly $\sigma$-donor ligands with only minor $\pi$-acceptor properties, is relatively weak as they can be easily exchanged by other ligands. This point was evidenced for the first time by Fukui and coworkers in 1975 while studying the reactivity of the chloride-bridged dinuclear $\mathrm{Pd}(\mathrm{II})$ complexes $\quad\left[\left\{\mathrm{PdCl}(\mu-\mathrm{Cl})\left(\mathrm{Ph}_{3} \mathrm{P}=\mathrm{NR}\right)\right\}_{2}\right] \quad\left(\mathrm{R}=4-\mathrm{C}_{6} \mathrm{H}_{4} \mathrm{CO}_{2} \mathrm{Et}, \quad 4-\mathrm{C}_{6} \mathrm{H}_{4} \mathrm{Me}\right)$ towards triphenylphosphine, triphenylphosphite and 2,2'-bipyridine. All these ligands were able to displace rapidly the coordinated iminophosphoranes $\mathrm{Ph}_{3} \mathrm{P}=\mathrm{NR}$ under very mild reaction conditions (room temperature) [10]. Despite this inherent lability, organometallic and 
coordination compounds comprising iminophosphorane ligands are being actively studied and found increasing applications in homogeneous catalysis. The most recent breakthroughs in the field are, among others, the development of highly active systems for the polymerization of olefins [11] and rac-lactide [12], or the design of robust water-soluble iminophosphoranes for catalytic transformations in environmentally friendly aqueous media [13]. This last point deserves to be highlighted given the sensitivity of $\mathrm{P}=\mathrm{N}$ bonds towards hydrolysis [2].

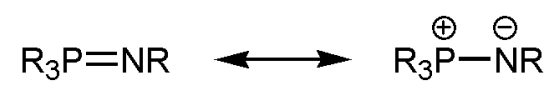

A

B

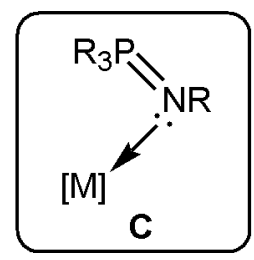

Figure 1. The two canonical forms of an iminophosphorane and its coordination to a metallic fragment.

The integration of supplementary donor sites into the iminophosphorane substituents yields polydentate mixed ligands, as those included in the generic metal complexes structures D-G depicted in Figure 2, capable of stabilizing a wider range of metal ions in comparison with their monodentate $\mathrm{R}_{3} \mathrm{P}=\mathrm{NR}$ counterparts. The proper selection and fine tuning of these additional donor sites, as well as the corresponding linkers, allows also the on-demand modulation of the reactivity of the metal center, a key point to achieve high activities and selectivities in catalysis. In addition, in these compounds, the weak iminophosphorane-metal bond may dissociate reversibly without the complete detachment of the ligand, thus opening a vacant coordination site on the metal for substrate binding while maintaining the catalyst integrity, i.e. they can present a hemilabile behaviour [14].

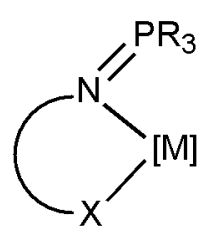

D

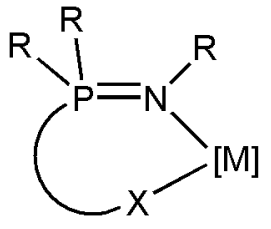

E

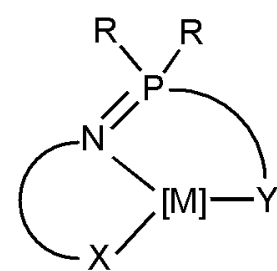

$\mathrm{F}$

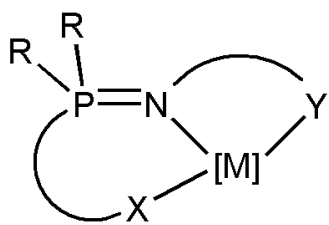

G

$\mathrm{X}$ and $\mathrm{Y}=\mathrm{N}-, \mathrm{P}-$, As-, $\mathrm{O}-$ or $\mathrm{C}-$ donor groups

Figure 2. Generic structures D-G of metal complexes with polydentate iminophosphorane-based ligands. 
Complexes bearing such polydentate ligands, particularly those featuring $P, N$-donor sets of type H-L (see Figure 3), have found several uses in homogeneous catalysis in recent years. Herein, an overview of the catalytic applications of these mixed iminophosphoranephosphine ligands is given [15-17].

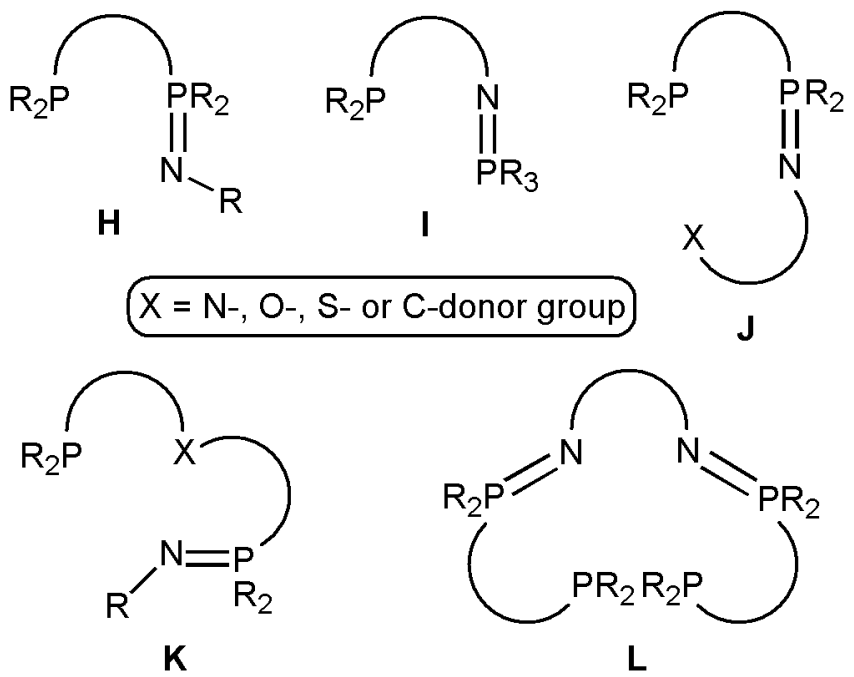

Figure 3. Different types of iminophosphorane-phosphine ligands employed in homogeneous catalysis.

\section{Hydrogenation and transfer hydrogenation reactions}

Metal-catalyzed hydrogenation reactions are among the most frequently encountered transformations in laboratories and industry, appearing as a core technology for the production of a large variety of commodity and fine chemicals, as well as pharmaceutical substances. Concerning the homogeneous version of these reactions, it is now well-accepted that high rates and selectivities are only attainable by the coordination of electronically and structurally well-defined ligands to the metal center [18]. In this sense, several $\mathrm{Rh}$ and $\mathrm{Ir}$ complexes containing iminophosphorane-phosphine ligands have been checked as potential catalysts for the selective hydrogenation of $\mathrm{C}=\mathrm{C}$ bonds.

First examples were described by Cavell and co-workers in 1994, who used the rhodium(I) complexes $\mathbf{1}$ and $\mathbf{2}$, in combination with $\mathrm{NEt}_{3}$, for the homogeneous hydrogenation of 1-hexene under mild conditions, i.e. at room temperature under a $\mathrm{H}_{2}$ pressure of 1.1 atm (Scheme 2) [19]. Thus, while isolated cationic species 1 gave only poor results (turnover frequency TOF $=0-9.5 \mathrm{~h}^{-1}$ ), catalytic solutions derived from freshly prepared mixtures of $\left[\{\mathrm{Rh}(\mu-\mathrm{Cl})(\operatorname{cod})\}_{2}\right](\operatorname{cod}=1,5$-cyclooctadiene $)$ and two equivalents of 
the appropriate iminophosphorane-phosphine ligand $\mathrm{Ph}_{2} \mathrm{P}-\mathrm{X}-\mathrm{P}(=\mathrm{NR}) \mathrm{Ph}_{2}$ showed a moderate reactivity $\left(\mathrm{TOF}=14.5-88 \mathrm{~h}^{-1}\right)$. This improvement in the catalytic activity was attributed by the authors to the higher solubility in ethanol of the complexes formed in situ as compared to the preformed hexafluophosphate salts $\mathbf{1}$.

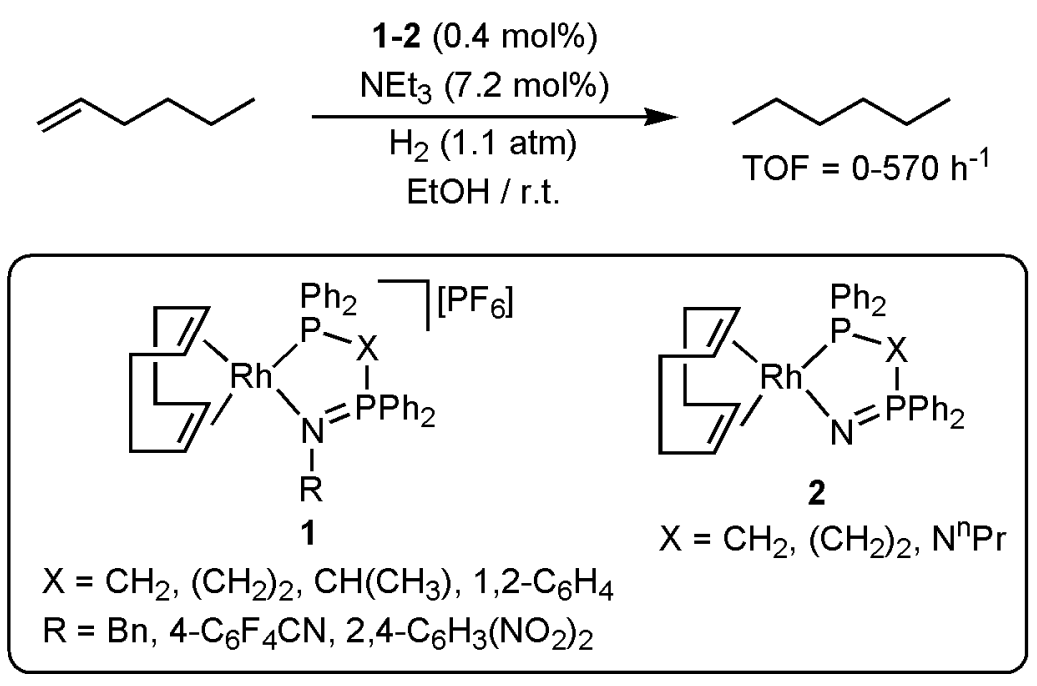

Scheme 2. Hydrogenation of 1-hexene catalyzed by the Rh(I) complexes 1-2.

Better results were obtained with the neutral complexes 2, generated in situ from $\left[\{\mathrm{Rh}(\mu-\mathrm{Cl})(\mathrm{cod})\}_{2}\right]$ and the $N$-silylated ligands $\mathrm{Ph}_{2} \mathrm{P}-\mathrm{X}-\mathrm{P}\left(=\mathrm{NSiMe}_{3}\right) \mathrm{Ph}_{2}\left(\mathrm{X}=\mathrm{CH}_{2},\left(\mathrm{CH}_{2}\right)_{2}\right.$, $\mathrm{N}^{\mathrm{n}} \mathrm{Pr}$ ) via $\mathrm{Me}_{3} \mathrm{SiCl}$ elimination, which showed catalytic activities (TOF values up to $570 \mathrm{~h}^{-1}$ ) comparable with those of the more classical systems $\left[\mathrm{Rh}(\operatorname{cod})\left(\mathrm{PPh}_{3}\right)_{2}\right]\left[\mathrm{PF}_{6}\right]\left(\mathrm{TOF}=236 \mathrm{~h}^{-1}\right)$, $\left[\mathrm{RhCl}\left(\mathrm{PPh}_{3}\right)_{3}\right] \quad\left(\mathrm{TOF}=380 \quad \mathrm{~h}^{-1}\right) \quad$ and $[\mathrm{Rh}(\mathrm{cod})(\mathrm{dppb})]\left[\mathrm{PF}_{6}\right] \quad(\mathrm{dppb}=1,4-$ bis(diphenylphosphino)butane; TOF $=570 \mathrm{~h}^{-1}$ ) tested under identical reaction conditions. Using the catalytic system $\left[\{\mathrm{Rh}(\mu-\mathrm{Cl})(\mathrm{cod})\}_{2}\right] / \mathrm{Ph}_{2} \mathrm{PCH}_{2} \mathrm{P}\left(=\mathrm{NSiMe}_{3}\right) \mathrm{Ph}_{2} / \mathrm{NEt}_{3}$, for which the best activity was found, the authors also investigated the effect of the solvent, ligand to rhodium ratio, and the role of the amine additive and co-solvents. The use of pure ethanol as solvent, a Rh / ligand ratio of 1:1, and an excess of the amine $\mathrm{NEt}_{3}\left(\mathrm{Rh}_{\text {/ }} \mathrm{NEt}_{3}\right.$ ratio of 1:18) led to the highest catalytic activity. Under these optimal conditions, other olefins, such as cyclohexene and styrene, were also hydrogenated (TOF $=660$ and $285 \mathrm{~h}^{-1}$, respectively) by the $\left[\{\mathrm{Rh}(\mu-\mathrm{Cl})(\mathrm{cod})\}_{2}\right] / \mathrm{Ph}_{2} \mathrm{PCH}_{2} \mathrm{P}\left(=\mathrm{NSiMe}_{3}\right) \mathrm{Ph}_{2}$ combination [19].

The hydrogenation of styrene catalyzed by the cationic rhodium(I) complex $\mathbf{3}$, containing a $N$-phosphorylated iminophosphorane-phosphine ligand coordinated in a chelating $\kappa^{2}-(P, O)$ manner, was described by Balakrishna and co-workers some years later (Scheme 3) [20]. In this case, using $0.0005 \mathrm{~mol} \%$ of $\mathbf{3}$ in combination with triethylamine (10 
mol\%), styrene could be converted quantitatively into ethylbenzene after 80 minutes in THF under mild conditions (i.e. $\mathrm{H}_{2}$ pressure of 4 atm at room temperature). This result implies a turnover number (TON) of 200000 and a turnover frequency (TOF) of $300000 \mathrm{~h}^{-1}$ (calculated at $50 \%$ conversion, i.e. $\mathrm{TOF}_{50}$ ), values that largely surpass those achieved by the Wilkinson's catalyst $\left[\mathrm{RhCl}\left(\mathrm{PPh}_{3}\right)_{3}\right]$, for which complete conversion at a low metal loading was observed under the following conditions: $0.0008 \mathrm{~mol} \%$ of $\left[\mathrm{RhCl}\left(\mathrm{PPh}_{3}\right)_{3}\right], \mathrm{T}=80{ }^{\circ} \mathrm{C}, \mathrm{P}\left(\mathrm{H}_{2}\right)=28 \mathrm{~atm}, \mathrm{t}$ $=2$ hours [21]. Moreover, the activity of $\mathbf{3}$ could be improved by increasing the $\mathrm{H}_{2}$ pressure to $10 \mathrm{~atm}$ and the temperature to $70{ }^{\circ} \mathrm{C}$, leading to a $\mathrm{TOF}_{50}$ value of $600000 \mathrm{~h}^{-1}$ under these new reaction conditions. Note that good results in terms of activity and selectivity were also reached in the catalytic hydrogenation of other olefins and terminal alkynes $(\alpha-$ methylstyrene, 4-methylstyrene and phenylacetylene) using the $\mathrm{Rh}(\mathrm{I})$ complex 3 [20].

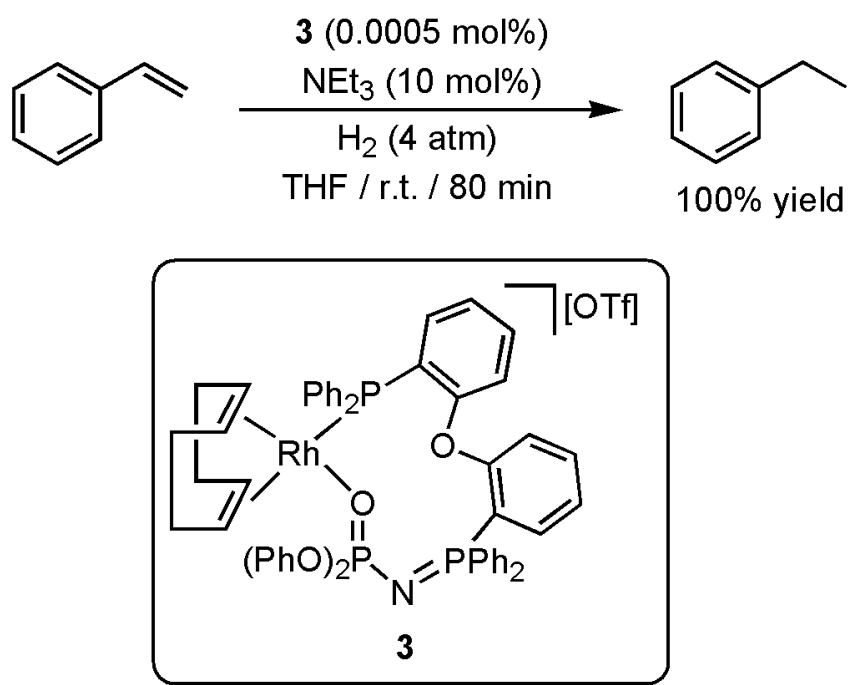

Scheme 3. Hydrogenation of styrene catalyzed by the cationic rhodium(I) complex $\mathbf{3}$.

Although to date little attention has been paid to the design of optically active iminophosphorane-phosphines [22-23], Kim and co-workers have demonstrated the enormous potential of this type of compounds in asymmetric catalysis. In particular, they described the preparation of the $P, N$-donor ligands $\mathbf{4 a - c}$ and $\mathbf{5 a - b}$ derived from planar-chiral ferrocenyl-diphosphines, anticipating that, as sterically demanding and robust chelating agents, they should accomplish high optical inductions in asymmetric reactions (Figure 4) [24]. Thus, in a first set of experiments, they performed the Rh-catalyzed asymmetric hydrogenation of the activated olefins $(E)$-2-methylcinnamic acid, $(Z)$-2-acetamidocinnamate and (Z)-2-acetamidoacrylate (see Scheme 4) [24a]. Reactions were conducted in methanol at $40{ }^{\circ} \mathrm{C}$, under a $\mathrm{H}_{2}$ pressure of $1 \mathrm{bar}$, and in the presence of $2 \mathrm{~mol} \%$ of the corresponding 
rhodium catalyst generated in situ from $\left[\mathrm{Rh}(\mathrm{nbd})_{2}\right]\left[\mathrm{BF}_{4}\right](\mathrm{nbd}=$ norbornadiene $)$ and a slight excess of 4a-c or 5a-b. The results obtained under these conditions are quite remarkable since high enantioselectivities (up to $99 \%$ ee) and catalytic activities (up to $100 \%$ yield) were achieved after 24 hours. As far as the nature of the ligands is concerned, the iminophosphorane-phosphines of $\mathbf{4 a - c}$ led in general to the poorer results in terms of activity, but proved to be the most effective with regard to the enantioselectivity. We must note that the enantiomeric excesses reached with 4a-c were also superior to those observed using the related ferrocenyl-bis(iminophosphoranes) 6a-c as ligands (Figure 4). It is also worthy of note that yields improvements could be achieved performing the catalytic reactions under 10 bar of $\mathrm{H}_{2}$, but with a concomitant slight erosion of the enantiomeric excesses.

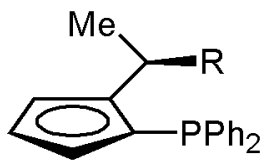

$\mathrm{Fe}$

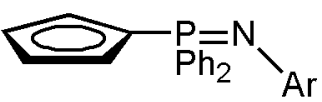

$\mathrm{R}=\mathrm{NMe}_{2} ; \mathrm{Ar}=2,6-\mathrm{C}_{6} \mathrm{H}_{3} \mathrm{Me}_{2}(\mathbf{4 a})$

$\mathrm{R}=\mathrm{NMe}_{2} ; \mathrm{Ar}=2,6-\mathrm{C}_{6} \mathrm{H}_{3}{ }^{\mathrm{i}} \mathrm{Pr}_{2}$ (4b)

$\mathrm{R}=\mathrm{OMe} ; \mathrm{Ar}=2,6-\mathrm{C}_{6} \mathrm{H}_{3} \mathrm{Me}_{2}$ (4c)

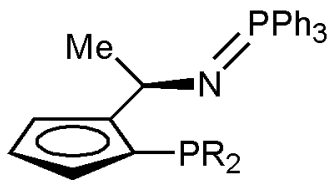

$\mathrm{Fe}$

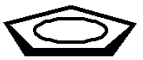

$\mathrm{R}=\mathrm{Ph}(\mathbf{5 a})$

$R=C y(5 b)$

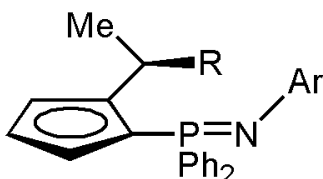

$\mathrm{Fe}$

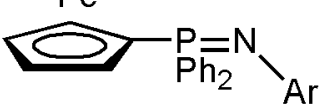

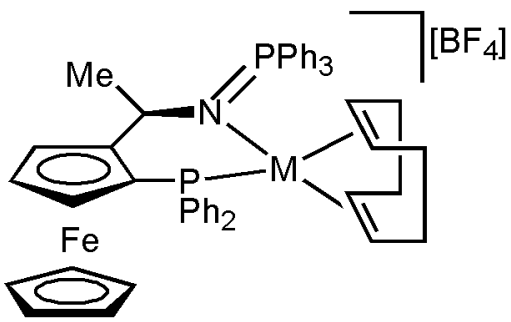

$$
\begin{aligned}
& M=\operatorname{Rh}(7) \\
& M=\operatorname{Ir}(8)
\end{aligned}
$$

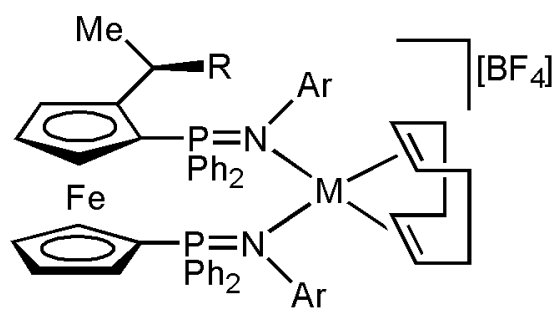

$$
\begin{aligned}
& R=N e_{2} ; A r=2,6-C_{6} H_{3} M_{2} ; M=R h(9 a), \operatorname{Ir}(10 a) \\
& R=N M e_{2} ; A r=2,6-C_{6} H_{3}{ }^{i} P_{2} ; M=R h(9 b), \operatorname{Ir}(10 b) \\
& R=O M e ; A r=2,6-C_{6} H_{3} M_{2} ; M=R h(9 c), \operatorname{Ir}(10 c)
\end{aligned}
$$

Figure 4. Structures of some optically active iminophosphorane-based ferrocenyl ligands and complexes. 

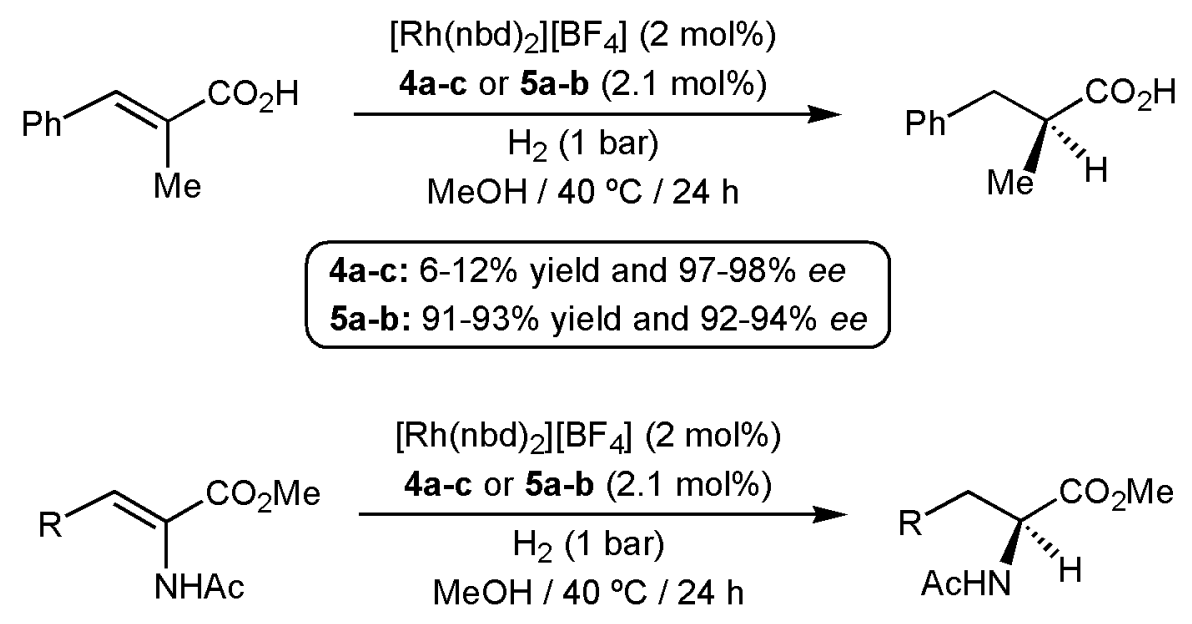

\begin{tabular}{|cc|}
\hline $\mathrm{R}=\mathrm{H}$ & $\mathrm{R}=\mathrm{Ph}$ \\
4a-c: $3-100 \%$ yield and $92-99 \%$ ee & 4a-c: $27-78 \%$ yield and $97-99 \%$ ee \\
5a-b: $100 \%$ yield and $74-82 \%$ ee & 5a-b: $70-86 \%$ yield and $68-73 \%$ ee \\
\hline
\end{tabular}

Scheme 4. Asymmetric hydrogenation of activated olefins catalyzed by $\mathrm{Rh}(\mathrm{I})$ complexes of $\mathbf{4 a - c}$ and $\mathbf{5 a - b}$.<smiles>C=C1CCCc2cc(OC)ccc21</smiles>

$\mathrm{Rh}(\mathrm{I})$ catalyst $7 ; 78 \%$ yield; $50 \%$ ee (R) Ir(I) catalyst 8; $99 \%$ yield; $48 \%$ ee $(R)$<smiles>C/C(=C\c1ccccc1)c1ccccc1</smiles>

$\mathrm{Rh}(\mathrm{l})$ catalyst 7; $98 \%$ yield; $46 \%$ ee (R) $\operatorname{Ir}(\mathrm{I})$ catalyst $8 ; 100 \%$ yield; $74 \%$ ee $(R)$<smiles>COc1ccc(C(C)=C(C)C)cc1</smiles>

$\operatorname{lr}(I)$ catalyst $8 ; 41 \%$ yield; $64 \%$ ee $(R)$<smiles>C=C(CC)c1ccc(OC)cc1</smiles>

$\mathrm{Rh}(\mathrm{I})$ catalyst 7; $99 \%$ yield; $69 \%$ ee $(R)$ Ir(l) catalyst $8 ; 100 \%$ yield; $80 \%$ ee $(R)$<smiles>COc1ccc2c(c1)CCC=C2C</smiles>

$\mathrm{Rh}(\mathrm{l})$ catalyst $7 ; 100 \%$ yield; $55 \%$ ee $(R)$ $\operatorname{Ir}(I)$ catalyst $8 ; 91 \%$ yield; $76 \%$ ee $(R)$<smiles>CC1=C(C)c2ccccc2C1</smiles>

$\operatorname{Ir}(I)$ catalyst $8 ; 87 \%$ yield; $59 \%$ ee (R)

Figure 5. Asymmetric hydrogenation of unfunctionalized di-, tri- and tetrasubstituted olefins by complexes 7-8.

Subsequently, the same authors employed the isolated complexes 7 and 8 (Figure 4), generated by reacting the cationic rhodium(I) and iridium(I) precursors $\left[\mathrm{M}(\operatorname{cod})_{2}\right]\left[\mathrm{BF}_{4}\right](\mathrm{M}=$ $\mathrm{Rh}$, Ir) with the iminophosphorane-phosphine 5a, for the asymmetric hydrogenation of various unactivated di-, tri-, and tetrasubstituted olefins [24b]. Reactions were conducted in 
methanol (7) or dichloromethane (8) at ambient temperature, under a $\mathrm{H}_{2}$ pressure of $10 \mathrm{bar}$, and in the presence of $2 \mathrm{~mol} \%$ of the appropriate complex for $24 \mathrm{~h}$. As shown in the selected examples given in Figure 5, high yields (78-100\%) were attained with both complexes in the hydrogenation of di- and trisubstituted alkenes, but only a moderate enantioselectivity was observed $(48-80 \%$ ee). In terms of chiral induction, the best results were in general observed with the $\operatorname{Ir}(\mathrm{I})$ catalyst $\mathbf{8}$, which proved to be also active in the hydrogenation of challenging tetrasubstituted olefins, the least reactive class of alkenes in hydrogenation reactions (Figure 5). We must note that the same hydrogenation processes were also performed with the related complexes 9-10a-c, derived from the chiral ferrocenyl-bis(iminophosphorane) ligands 6a-c (Figure 4), leading in most cases to higher enantiomeric excesses (up to 99\% ee).
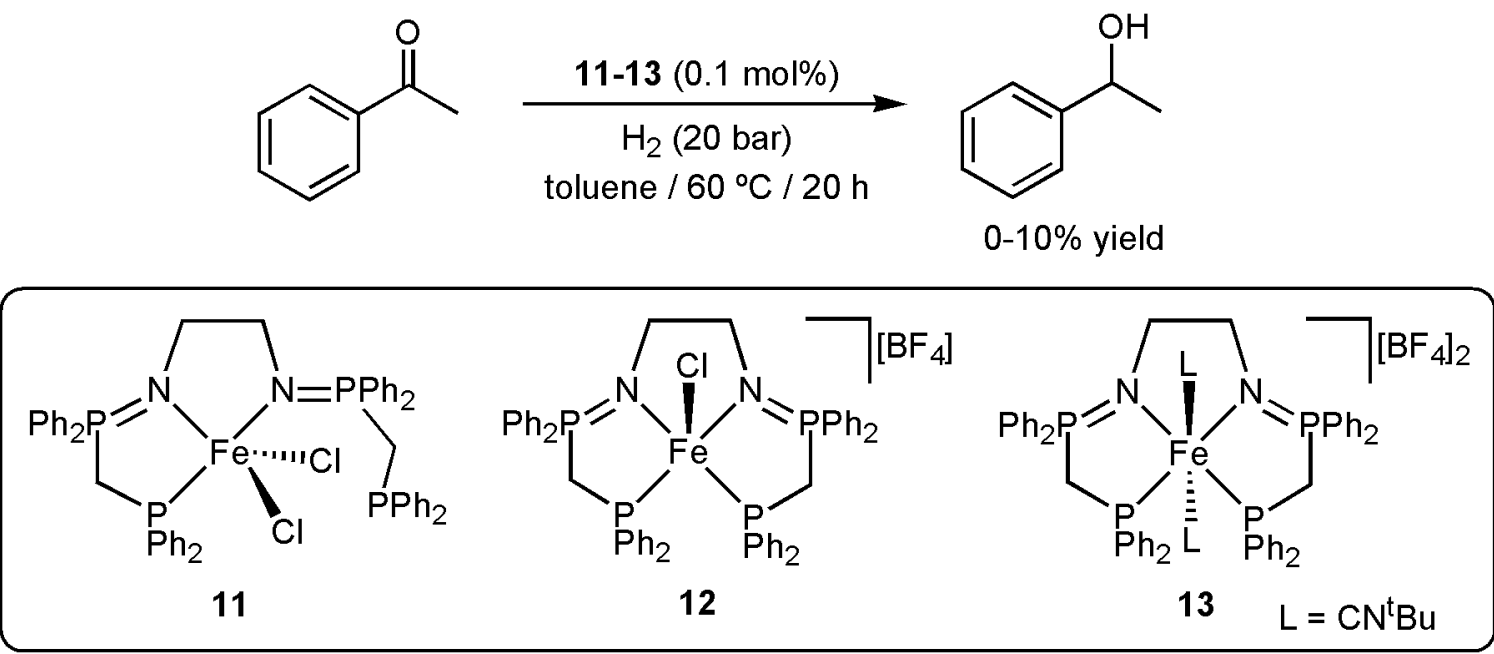<smiles>CC(=O)c1ccccc1</smiles>

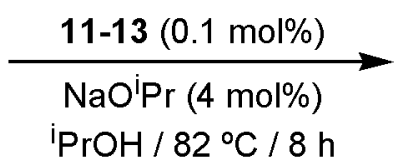<smiles>CC(O)c1ccccc1</smiles>

$75-80 \%$ yield

Scheme 5. Iron-catalyzed hydrogenation and transfer hydrogenation of acetophenone.

On the other hand, recent years have seen the growing development of iron catalysts for $\mathrm{C}=\mathrm{O}$ reductions as an alternative to the use of more expensive metals such as ruthenium or rhodium [25]. In this context, the ability of the iron(II) complexes 11-13, containing a tetradentate bis(iminophosphorane-phosphine) ligand, to promote the hydrogenation of acetophenone to 1-phenylethanol was checked by Le Floch and co-workers (Scheme 5) [26]. Disappointingly, using a catalyst loading of $0.1 \mathrm{~mol} \%$ and $\mathrm{H}_{2}$ pressure of $20 \mathrm{bar}$, no reaction was observed after 20 hours in toluene at $60^{\circ} \mathrm{C}$ for 11 and $\mathbf{1 3}$, while 12 only reached $10 \%$ of conversion. Otherwise, much better results were obtained when the reduction of 
acetophenone by complexes 11-13 was performed under transfer hydrogenation (TH) conditions [26]. The $\mathrm{TH}$ of unsaturated organic compounds using H-donor solvents constitutes a safer alternative to the classical catalytic hydrogenations since it requires neither the use of highly flammable molecular hydrogen nor pressure vessels, and it is easier to execute [27]. Thus, employing 2-propanol as solvent and hydrogen source, all the three complexes, in combination with the base $\mathrm{NaO}^{\mathrm{i}} \mathrm{Pr}$, proved to be active in the reduction process leading to 1 -phenylethanol in $75-80 \%$ yield after $8 \mathrm{~h}$ of heating at $82{ }^{\circ} \mathrm{C}$ (Scheme 5).

Further studies by Le Floch and Auffrant also demonstrated the utility of the related $\mathrm{Rh}$ (III) complex 14 for the transfer hydrogenation of a series of acetophenone derivatives (Scheme 6) [28]. The reactions, conducted in refluxing 2-propanol with 1 mol\% of 14 and 10 mol\% of $\mathrm{NaO}^{\mathrm{i}} \mathrm{Pr}$, delivered the desired alcohols in $\geq 96 \%$ yield after $8-18 \mathrm{~h}$. Regarding the mechanism of these catalytic reactions, the authors demonstrated that reduction of $\mathbf{1 4}$ by $\mathrm{NaO}^{\mathrm{i}} \mathrm{Pr}$ takes place under the experimental conditions employed, leading to the $\mathrm{Rh}(\mathrm{I})$ derivative 15. This complex could be independently synthesized and proved to be more active than 14 in the reduction of the model acetophenone substrate (100\% yield of 1phenylethanol after only $4 \mathrm{~h}$ of heating). Worthy of note, employing the same experimental conditions, the $\mathrm{Rh}(\mathrm{III})$ complex 14 was able to convert $\mathrm{PhC}(\mathrm{H})=\mathrm{NPh}$ into $\mathrm{PhCH}_{2} \mathrm{~N}(\mathrm{H}) \mathrm{Ph}$, albeit in moderate yield ( $67 \%$ after $24 \mathrm{~h}$ ). To the best of our knowledge, this is the only example reported to date in the literature for the $\mathrm{TH}$ of an imine catalyzed by an iminophosphorane-based complex.<smiles>[R]c1ccc(C(C)=O)cc1</smiles>

$\mathrm{R}=\mathrm{H}, \mathrm{Cl}, \mathrm{Me}, \mathrm{OMe}$

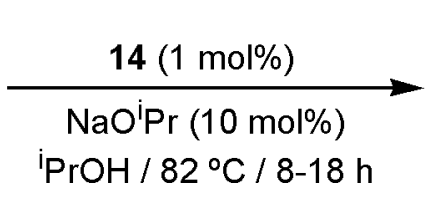

$\mathrm{PrOH} / 82^{\circ} \mathrm{C} / 8-18 \mathrm{~h}$<smiles>[R]c1ccc(C(C)O)cc1</smiles>

$96-99 \%$ yield

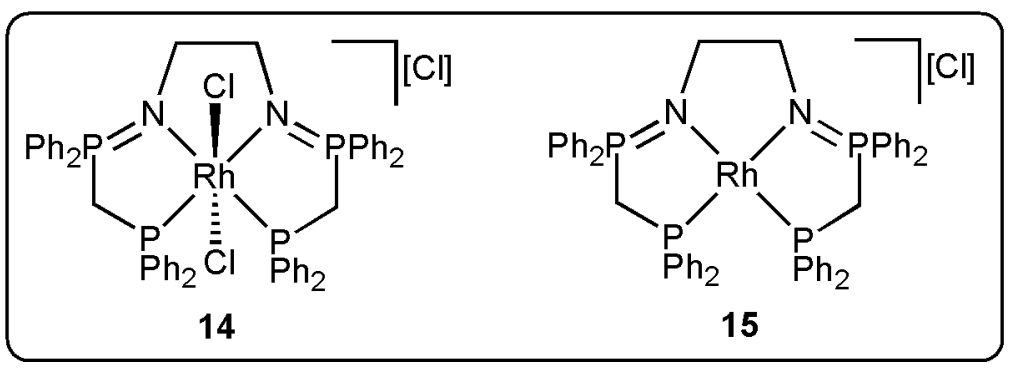

Scheme 6. Rhodium-catalyzed transfer hydrogenation of acetophenone derivatives. 
Ruthenium compounds are known to be particularly effective in transfer hydrogenation reactions [27]. In this context, the first examples of ruthenium catalysts based on iminophosphorane-phosphine ligands were described by Gimeno and co-workers in 2002 [29]. They successfully employed the half-sandwhich $\left(\eta^{6}\right.$-arene)-ruthenium(II) complexes 16-17a-f, containing the fluorinated hemilabile iminophosphorane-phosphine $\mathrm{Ph}_{2} \mathrm{PCH}_{2} \mathrm{P}(=\mathrm{N}$ $\left.p-\mathrm{C}_{5} \mathrm{~F}_{4} \mathrm{~N}\right) \mathrm{Ph}_{2}$ coordinated in both $\kappa^{1}-(P)$ and $\kappa^{2}-(P, N)$ manners [30], to promote the reduction of cyclohexanone to cyclohexanol by 2-propanol (Scheme 7). Remarkably, while the coordination mode adopted by $\mathrm{Ph}_{2} \mathrm{PCH}_{2} \mathrm{P}\left(=\mathrm{N}-p-\mathrm{C}_{5} \mathrm{~F}_{4} \mathrm{~N}\right) \mathrm{Ph}_{2}$ showed only a little effect, a marked influence of the arene ligand on the catalytic activity of these systems was observed, with those complexes bearing the bulkier and electronically richer arene $\mathrm{C}_{6} \mathrm{Me}_{6}$ showing the best performances. In particular, using the cationic derivative $\left[\operatorname{RuCl}\left(\eta^{6}-\mathrm{C}_{6} \mathrm{Me}_{6}\right)\left\{\kappa^{2}-(P, N)-\right.\right.$ $\left.\left.\mathrm{Ph}_{2} \mathrm{PCH}_{2} \mathrm{P}\left(=\mathrm{N}-p-\mathrm{C}_{5} \mathrm{~F}_{4} \mathrm{~N}\right) \mathrm{Ph}_{2}\right\}\right]\left[\mathrm{SbF}_{6}\right]$ (17f) almost quantitative formation of cyclohexanol was reached after only $1 \mathrm{~h}\left(\mathrm{TOF}_{50}=249 \mathrm{~h}^{-1}\right)$.

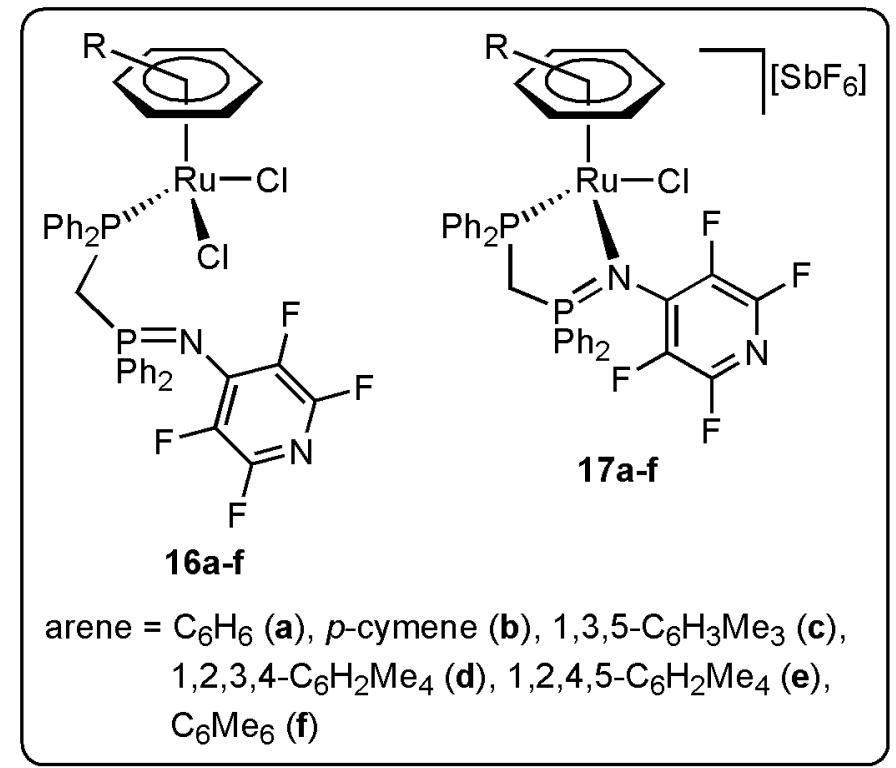<smiles>O=C1CCCCC1</smiles>

16-17a-f $(0.4 \mathrm{~mol} \%)$ $\mathrm{NaOH}(9.6 \mathrm{~mol} \%)$ i $\mathrm{PrOH} / 82^{\circ} \mathrm{C} / 1-24 \mathrm{~h}$

Scheme 7. Ruthenium-catalyzed transfer hydrogenation of cyclohexanone.

Using the TH of cyclohexanone as model reaction, the same authors also explored the catalytic behaviour of different series of ( $\eta^{6}-p$-cymene)-ruthenium(II) 18-21a-d and bis(allyl)-ruthenium(IV) 22-24a-d complexes bearing $N$-phosphorylated $(\mathrm{X}=\mathrm{O})$ and $N$ thiophosphorylated $(\mathrm{X}=\mathrm{S})$ iminophosphorane-phosphine ligands of general composition $\mathrm{Ph}_{2} \mathrm{PCH}_{2} \mathrm{P}\left\{=\mathrm{NP}(=\mathrm{X})(\mathrm{OR})_{2}\right\} \mathrm{Ph}_{2}(\mathrm{R}=\mathrm{Et}, \mathrm{Ph})$, which are able to coordinate the ruthenium centers in $\kappa^{1}-(P), \kappa^{2}-(P, N), \kappa^{2}-(P, X)$ or $\kappa^{3}-(P, N, X)$ manner (Figure 6) [31]. 


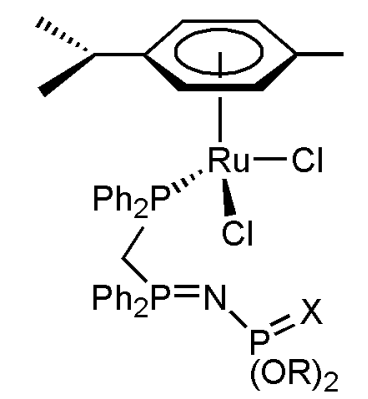

$X=O ; R=E t$ (18a), $P h(\mathbf{1 8 b})$

$X=S ; R=E t(18 c), P h(18 d)$

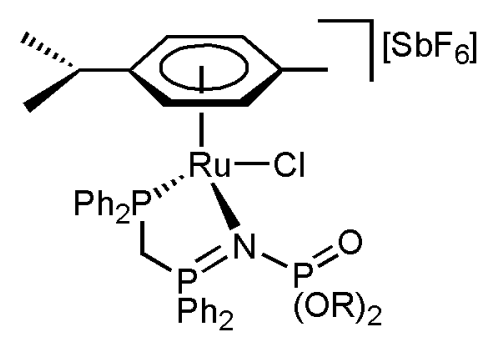

$\mathrm{R}=\mathrm{Et}(\mathbf{1 9 a})$

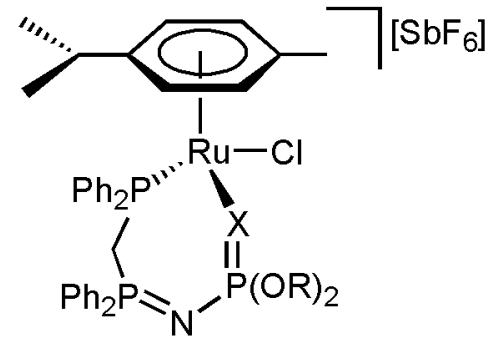

$X=O ; R=E t ~(20 a), P h(20 b)$

$X=S ; R=E t(20 c), P h(20 d)$

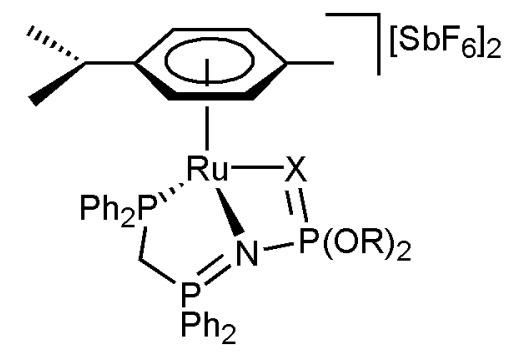

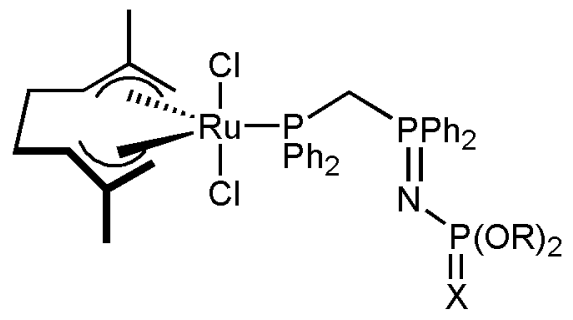

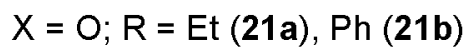

$X=O ; R=E t(22 a), P h(22 b)$

$X=S ; R=E t(21 c), P h(21 d)$

$X=S ; R=E t(22 c), P h(22 d)$
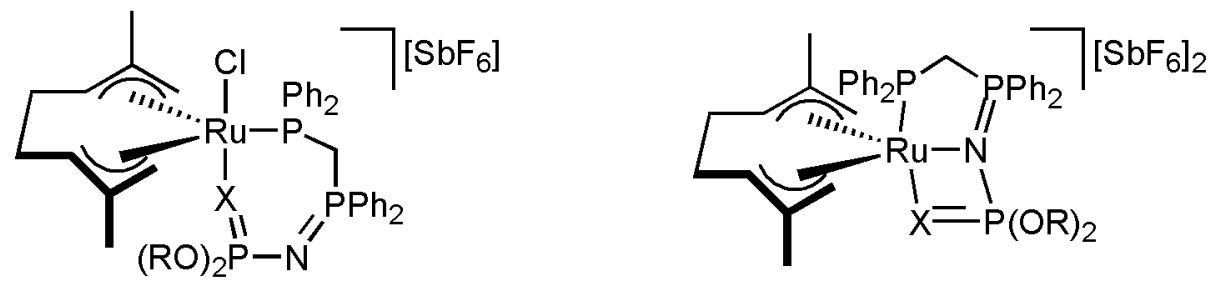

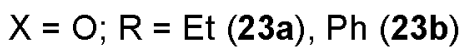

$X=O ; R=E t(24 a), P h$ (24b)

$X=S ; R=E t(23 c), P h(23 d)$

$X=S ; R=E t(24 c), P h(24 d)$

Figure 6. Structures of iminophosphorane-phosphine-Ru(II) and $\mathrm{Ru}(\mathrm{IV})$ complexes active in TH reactions.

All the complexes resulted active in the reduction process and no direct relationship between the catalytic activity and the coordination mode adopted by the iminophosphoranephosphine ligands was again observed. This fact is in complete accord with the hemilabile behavior shown by all these complexes in solution. Additionally, in contrast to the similar catalytic efficiencies found by the authors for both phosphorylated- $(X=O ; \mathbf{1 8 - 2 1 a - b})$ and thiophosphorylated-ruthenium(II) (X = S; 18-21c-d) complexes, the thiophosphorylatedruthenium(IV) derivatives $\mathbf{2 2 - 2 4 c - d}$ were comparatively more active than their phosphorylated counterparts 22-24a-b $\left(\mathrm{TOF}_{50}=150-1600 v s 12-426 \mathrm{~h}^{-1}\right)$. This is particularly remarkable in the case of the most active $\mathrm{Ru}(\mathrm{IV})$ complexes $\left[\mathrm{Ru}\left(\eta^{3}: \eta^{3}-\mathrm{C}_{10} \mathrm{H}_{16}\right) \mathrm{Cl}\left(\kappa^{2}-(P, X)-\right.\right.$ $\left.\left.\mathrm{Ph}_{2} \mathrm{PCH}_{2} \mathrm{P}\left\{=\mathrm{NP}(=\mathrm{X})(\mathrm{OEt})_{2}\right\} \mathrm{Ph}_{2}\right)\right]\left[\mathrm{SbF}_{6}\right]\left(\mathrm{TOF}_{50}=426 \mathrm{~h}^{-1}(\mathrm{X}=\mathrm{O} ; \mathbf{2 3 a})\right.$ vs $1600 \mathrm{~h}^{-1}(\mathrm{X}=\mathrm{S}$; 23c)). 
Table 1. Catalytic transfer hydrogenation of ketones by the Ru(IV) complex 23c.

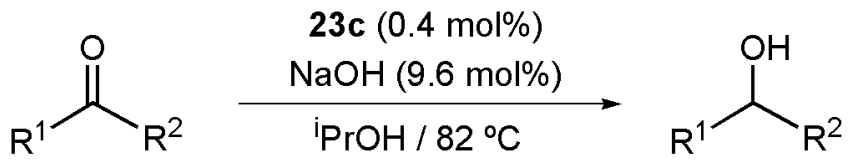

\begin{tabular}{llllll}
\hline Entry & $\mathrm{R}^{1}$ & $\mathrm{R}^{2}$ & Time (h) & Yield $(\%)^{a}$ & $\mathrm{TOF}_{50}\left(\mathrm{~h}^{-1}\right)^{b}$ \\
\hline 1 & \multicolumn{2}{c}{$-\left(\mathrm{CH}_{2}\right)_{6^{-}}$} & 4 & $>99$ & 1600 \\
2 & \multicolumn{2}{c}{$-\left(\mathrm{CH}_{2}\right)_{5}{ }^{-}$} & 9 & 98 & 480 \\
3 & $\mathrm{Me}$ & $\mathrm{Et}$ & 24 & 96 & 90 \\
4 & $\mathrm{Me}$ & ${ }^{\mathrm{i}} \mathrm{Pr}$ & 24 & 76 & 30 \\
5 & $\mathrm{Me}$ & $\mathrm{Ph}$ & 24 & 91 & 30 \\
6 & $\mathrm{Me}$ & $4-\mathrm{C}_{6} \mathrm{H}_{4} \mathrm{OMe}$ & 24 & 73 & 20 \\
7 & $\mathrm{Me}$ & $4-\mathrm{C}_{6} \mathrm{H}_{4} \mathrm{Cl}$ & 9 & 96 & 140 \\
8 & $\mathrm{Me}$ & $4-\mathrm{C}_{6} \mathrm{H}_{4} \mathrm{Br}$ & 24 & 98 & 90 \\
9 & $\mathrm{Me}$ & $3-\mathrm{C}_{6} \mathrm{H}_{4} \mathrm{Br}$ & 24 & 99 & 130 \\
10 & $\mathrm{Me}$ & $2-\mathrm{C}_{6} \mathrm{H}_{4} \mathrm{Br}$ & 24 & 42 & --- \\
\hline
\end{tabular}

${ }^{a}$ Determined by GC. ${ }^{b}$ Turnover frequencies ((mol product/mol catalyst)/time) calculated at $50 \%$ conversion.

In addition to cyclohexanone, the most active complex 23c was also tested in the transfer hydrogenation of other ketones [31b]. As shown in Table 1, this $R u(I V)$ catalyst proved to be effective in the reduction of various dialkyl ketones (entries 1-4) although its catalytic activity was significantly reduced when bulky substituents are present (i.e. $\mathrm{Me}(\mathrm{Et}) \mathrm{CO}$ vs $\mathrm{Me}\left({ }^{\mathrm{i}} \mathrm{Pr}\right) \mathrm{CO}$; entry 3 vs 4). Slow reductions were also found for aryl ketones, including acetophenone and its ortho-, meta-, and para-substituted derivatives (entries 5-10). It is apparent that the introduction of electron-withdrawing groups $(\mathrm{Cl}, \mathrm{Br})$ in the para or meta position of the aromatic ring allowed faster conversions (entries 7-9 vs 5), while a contrary effect was observed when a electron-donor group (i.e. OMe; entry $6 v s$ ) is present.

From a mechanistic point of view, the catalytic transfer hydrogenation reactions can proceed through two fundamentally different pathways [27]. For main group metals, the hydrogen transfer usually occurs directly from the donor to the substrate (transition state $\mathbf{M}$ in Figure 7), while for transition-metal catalysts hydrogen is delivered in a stepwise manner by first forming a metal-hydride intermediate. This latter route can further proceed via an 
inner-sphere pathway, involving coordination of the carbonyl compound to the metal (transition state $\mathbf{N}$ ), or through an outer-sphere variant without direct substrate-metal bonding (transition state $\mathbf{O}$ ). In this sense, although no mechanistic studies were performed, the most classical pathway $\mathbf{N}$ was proposed for the transfer hydrogenation reactions catalyzed by the iminophosphorane-phosphine ruthenium complexes 16-17a-f and 18-24a-d [29,31].<smiles>[R]C([R])([R])[C@H]1O[M]OC1(C)C</smiles>

M<smiles>[R]C1([R])[M]O[CH]1</smiles>

$\mathrm{N}$<smiles>[R][C@H]1[CH][CH][Y][CH]C1([R])[R]</smiles>

0

Figure 7. Proposed transition states in catalytic transfer hydrogenation reactions.

On the contrary, Sabo-Etienne and co-workers have postulated that, due to the presence of cooperative $\mathrm{N}-\mathrm{H}$ functionalities on the auxiliary iminophosphorane-phosphine ligand, the dihydrogen and hydrido Ru(II) complexes 25-27 operate through an outer-sphere mechanism (Figure 8) [32]. Using a ruthenium loading of $1 \mathrm{~mol} \%$ and $10 \mathrm{~mol} \%$ of sodium (to generate in situ the $\mathrm{NaO}^{\mathrm{i}} \mathrm{Pr}$ base), these species were able to transform acetophenone into 1phenylethanol in $91-94 \%$ yield after 6 hours of heating at $80{ }^{\circ} \mathrm{C}$ in 2 -propanol. The hydrido compounds 26 and 27 were even active in the absence of $\mathrm{Na}$, although the conversions achieved under these conditions were significantly lower (79-84\% yield after $24 \mathrm{~h})$. The catalytic experiments carried out with complexes $\mathbf{2 5}$ and $\mathbf{2 6}$ led to the precipitation of a large quantity of neutral monohydride species 27 a few minutes after immersion of the reaction vessel into the $80^{\circ} \mathrm{C}$ preheated oil bath, whereas in an independent experiment reprotonation of isolated 27 to 26 could be easily achieved in the presence of ${ }^{\mathrm{i}} \mathrm{PrOH}$. These key observations strongly support an outer-sphere mechanism in which the functionalized iminophosphorane-phosphine ligand actively participates in the transfer of hydrogen to the substrate. The related Ru(II) complexes 28 and 29 have also been employed in the TH of acetophenone, but their effectiveness was found to be comparatively lower [33]. 


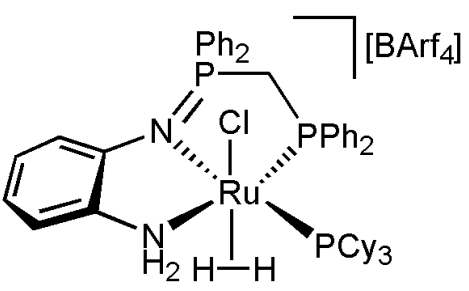

25

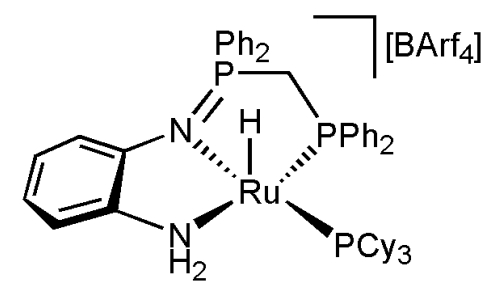

26

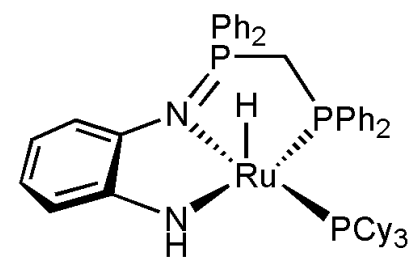

27

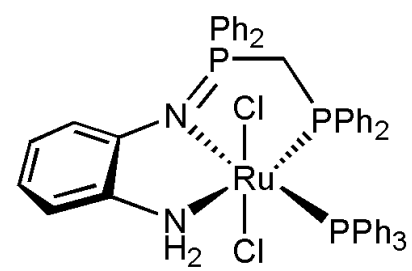

28

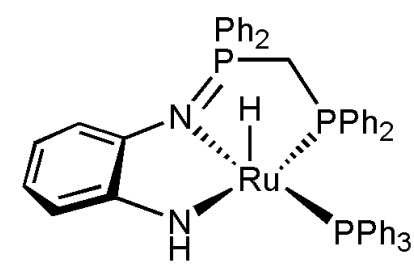

29

Figure 8. Structures of the iminophosphorane-phosphine-ruthenium(II) complexes 25-29.

In addition, in order to gain some information on the chemoselectivity of the process the transfer hydrogenation of 5-hexen-2-one was studied using the neutral hydrido complex 27 as catalyst [32]. As shown in Scheme 8, preferential reduction of the ketone functionality over the olefinic one was observed, the reaction leading to the formation of 5-hexen-2-ol with $96 \%$ selectivity. Similar results were attained with the hydrido-Ru(II) derivatives $\mathbf{3 0}$ and 31 supported by a tetradentate bis(iminophosphorane-phosphine) ligand (Scheme 8) [34]. As expected, these latter complexes proved also effective in the reduction of acetophenone (95$96 \%$ yield of 1-phenylethanol after $6 \mathrm{~h}$ at $80^{\circ} \mathrm{C}$ using $1 \mathrm{~mol} \%$ of Ru) [34].
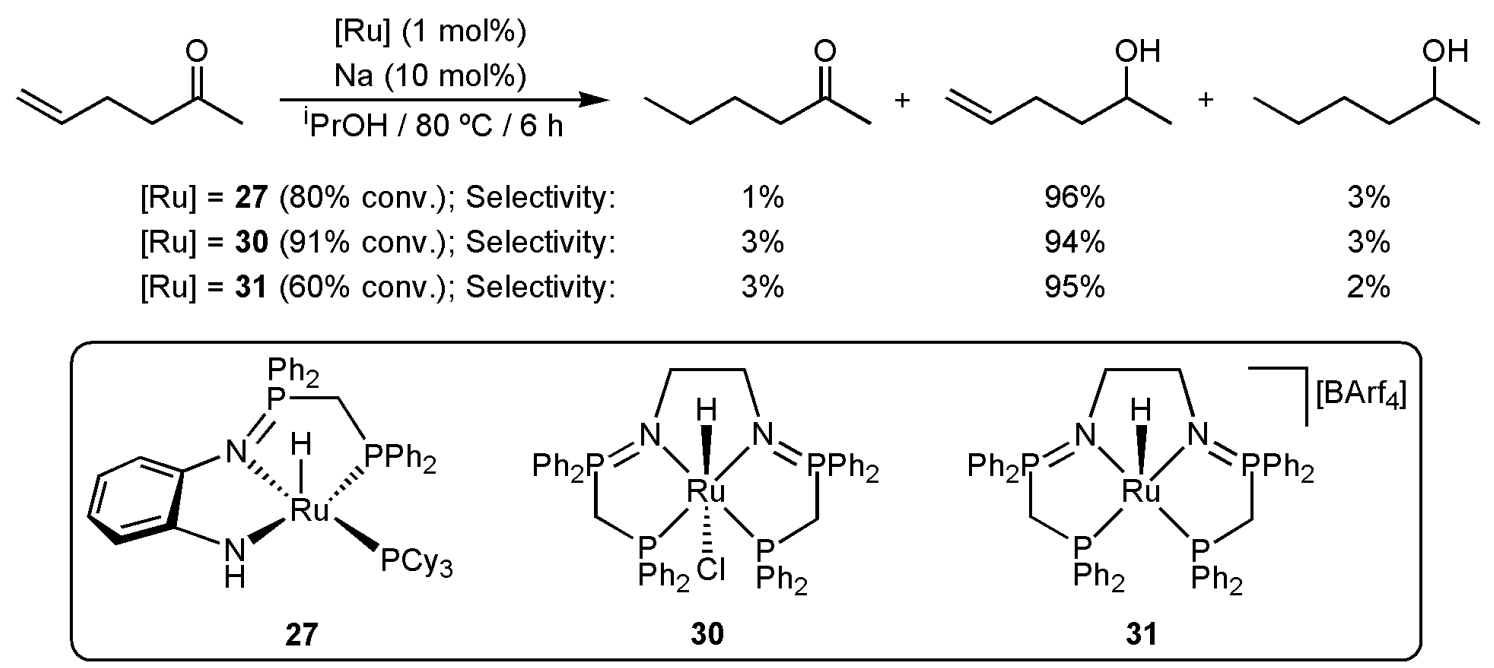

Scheme 8. Catalytic transfer hydrogenation of 5-hexen-2-one using complexes $\mathbf{2 7}, \mathbf{3 0}$ and $\mathbf{3 1}$ as catalysts.

\section{Cross-coupling reactions}


Metal-catalyzed cross-coupling reactions between an organic electrophile, typically an organic halide, and an organic nucleophile have developed into a standard component of the synthetic chemistry toolbox for the formation of C-C and C-heteroatom bonds [35]. Palladium-catalyzed reactions, which can be generally carried out under milder conditions and with a wider range of substrates than reactions promoted by other metals, clearly dominate the field. The organic halide can be a sp-, $\mathrm{sp}^{2}$-, or $\mathrm{sp}^{3}$-hybridized carbon with any halogen or pseudo-halogen leaving group. A variety of name reactions have been developed using organometallic carbon nucleophiles. Examples with nearly every metal in the periodic table have been demonstrated, but the most common organometallic species used include organotin (Stille), organoboron (Suzuki-Miyaura), Grignard reagents (Kumada-Corriu), organosilicon (Hiyama), organozinc (Negishi), and in situ generated acetylide anions (Sonogashira).

The Sonogashira cross-coupling is probably the most straightforward and powerful method presently available for the catalytic construction of $\mathrm{C}\left(\mathrm{sp}^{2}\right)-\mathrm{C}(\mathrm{sp})$ bonds, providing an efficient route for the synthesis of aryl- or heteroaryl-alkynes [35,36]. Typically, two catalysts are needed for this reaction, a palladium complex and a halide salt of copper(I), and an amine as solvent or in a large excess. The requirement of a $\mathrm{Cu}(\mathrm{I})$ co-catalyst, that can induce competitive homocoupling reactions of terminal alkynes to diynes in the presence of oxygen, and the large excess of amine needed are however major drawbacks. In this sense, the palladium(II) complex 32 (Figure 9), containing a ferrocene-based iminophosphoranephosphine ligand, was reported by Molina and Arques as an efficient catalyst for the amineand copper-free Sonogashira reaction [37].

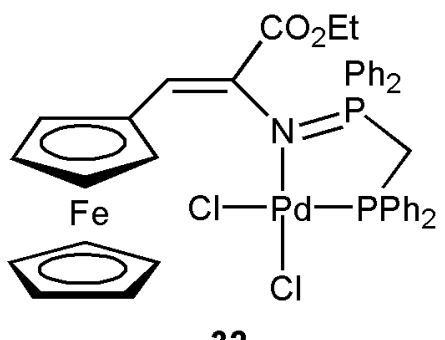

32

Figure 9. Structures of the iminophosphorane-phosphine-palladium(II) complex 32. 
Table 2. Amine- and copper-free Sonogashira couplings catalyzed by complex $32 .{ }^{a}$

$$
\mathrm{Ar}-\mathrm{X}+\mathrm{R}=\frac{\mathbf{3 2}(0.1 \mathrm{~mol} \%)}{\mathrm{NBAOAc}(1.5 \text { equiv. })} \underset{\mathrm{NMP} / 110^{\circ} \mathrm{C} / 1 \mathrm{~h}}{\mathrm{R}}=\mathrm{Ar}
$$

\begin{tabular}{|c|c|c|c|}
\hline Entry & Ar-X & Alkyne & Yield $(\%)^{b}$ \\
\hline 1 & & & $98(96)$ \\
\hline 2 & & & > 99 (99) \\
\hline 3 & & & $96(94)$ \\
\hline 4 & & & $>99(97)$ \\
\hline 5 & & & $84(83)$ \\
\hline 6 & & & $94(92)$ \\
\hline 7 & & & $72(70)$ \\
\hline 8 & & & $96(90)$ \\
\hline 9 & & & 99 \\
\hline 10 & & & $>99(97)$ \\
\hline 11 & & & $>99(98)$ \\
\hline 12 & & & $65(64)$ \\
\hline
\end{tabular}

${ }^{a}$ Reactions performed using $1 \mathrm{mmol}$ of aryl halide and $1.2 \mathrm{mmol}$ of alkyne. ${ }^{b}$ Determined by GC (isolated yield after work-up in brackets). 
Studying the C-C coupling of 2-methoxy-iodobenzene with phenylacetylene as model, and using NMP ( $N$-methylpyrrolidinone) as solvent in the presence of the activator TBAOAc (tetrabutylammonium acetate), they found that the reaction proceeded cleanly at room temperature with a catalyst loading of $1 \mathrm{~mol} \%$, leading to the desired arylacetylene product in $85 \%$ yield after 27 hours. By rising up the temperature to $110^{\circ} \mathrm{C}$, the yield improved to $98 \%$ in only 1 hour. In addition, with the increasing of the temperature, the catalyst loading could be reduced to $0.1 \mathrm{~mol} \%$ (entry 1, Table 2). Employing these optimized reaction conditions, the catalytic system was successfully extended to other aromatic and heteroaromatic iodides and bromides in the coupling reaction with phenylacetylene (entries 2-9, Table 2) and ferrocenylacetylene (entries 10-12, Table 2). Good to excellent products yields were in all the cases observed. Remarkably, the palladium(II) catalyst $\mathbf{3 2}$ was found to be relatively insensitive to the steric hindrance of the starting halide, and it also showed a good tolerance to functional groups.

To explore the scope of this catalytic system, deactivated trialkylsilyl-protected acetylenes, which are known to be more difficult to couple under copper-free conditions, were used in the Sonogashira cross-coupling reaction. Thus, while the use of trimethylsilylacetylene was inefficient due to the significant desilylation of the product that takes place under the reaction conditions to give symmetrically disubstituted alkynes, the use of triisopropylsilylacetylene gave rise to the desired mono-aryl-substituted alkynes in excellent yields (Scheme 9) [37].

$$
\begin{aligned}
& 32(0.1 \mathrm{~mol} \%) \\
& \mathrm{Ar}-\mathrm{l}+\equiv \mathrm{SiMe}_{3} \underset{\mathrm{NMP} / 110^{\circ} \mathrm{C} / 1-2 \mathrm{~h}}{\operatorname{TBAOAc}(1.5 \text { equiv. }} \rightarrow \mathrm{Ar}=\mathrm{Ar} \\
& \mathrm{Ar}=4-\mathrm{C}_{6} \mathrm{H}_{4} \mathrm{OMe}, 4-\mathrm{C}_{6} \mathrm{H}_{4} \mathrm{Me}, \text { 2-thienyl } \\
& 72-93 \% \text { yield }
\end{aligned}
$$

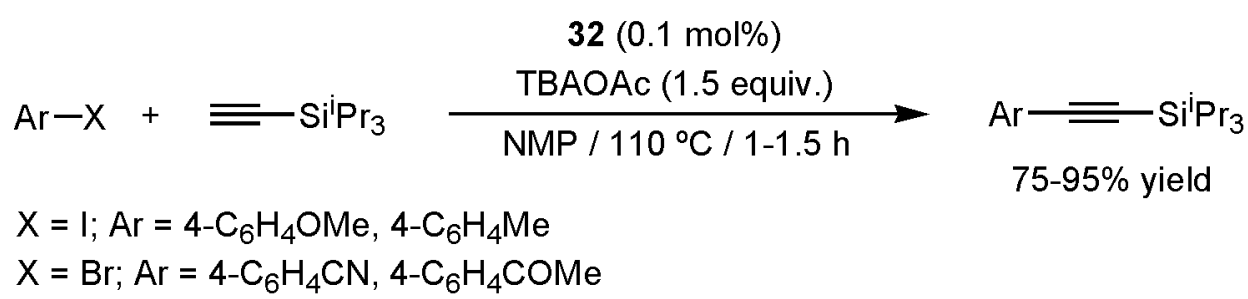

Scheme 9. Amine- and copper-free Sonogashira couplings of trialkylsilyl-proptected alkynes catalyzed by 32.

The ability of complex 32 to promote aryl-amination $\mathrm{C}-\mathrm{N}$ couplings has also been briefly described using 4-iodotoluene and $N$-benzylmethylamine as model substrates (Scheme 10) [38]. The best result was obtained when a mixture of 4-iodotoluene (1 equiv.), 
$N$-benzylmethylamine ( 3 equiv.) and $\mathrm{NaO}^{t} \mathrm{Bu}\left(1.4\right.$ equiv.) was heated in dioxane at $160{ }^{\circ} \mathrm{C}$ for $24 \mathrm{~h}$ in the presence of $1.5 \mathrm{~mol} \%$ of 32 , the reaction leading to the corresponding arylamine in $75 \%$ yield.

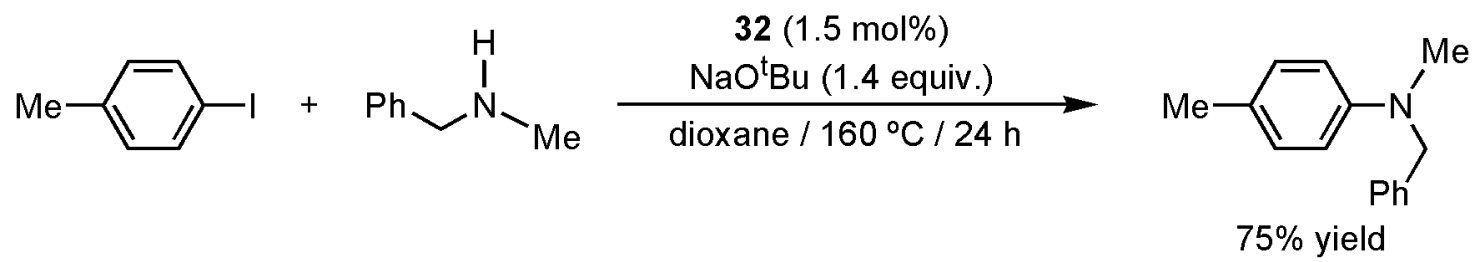

Scheme 10. Arylamination of 4-iodotoluene with $N$-benzylmethylamine catalyzed by the $\mathrm{Pd}(\mathrm{II})$ complex 32 .

Due to the particular usefulness of Suzuki-Miyaura-type cross-coupling reactions, Akira Suzuki was awarded with the Nobel Prize in Chemistry in 2010. The Suzuki-Miyaura reaction consists in the $\mathrm{C}\left(\mathrm{sp}^{2}\right)-\mathrm{C}\left(\mathrm{sp}^{2}\right)$ coupling of an aryl- or vinyl-boron derivative with an aryl- or vinyl-halide catalyzed by palladium or nickel [35,39]. In this context, it has been reported that the iminophosphorane-phosphine-based complexes 33-35 (Figure 10) are able to promote such $\mathrm{C}-\mathrm{C}$ coupling processes.
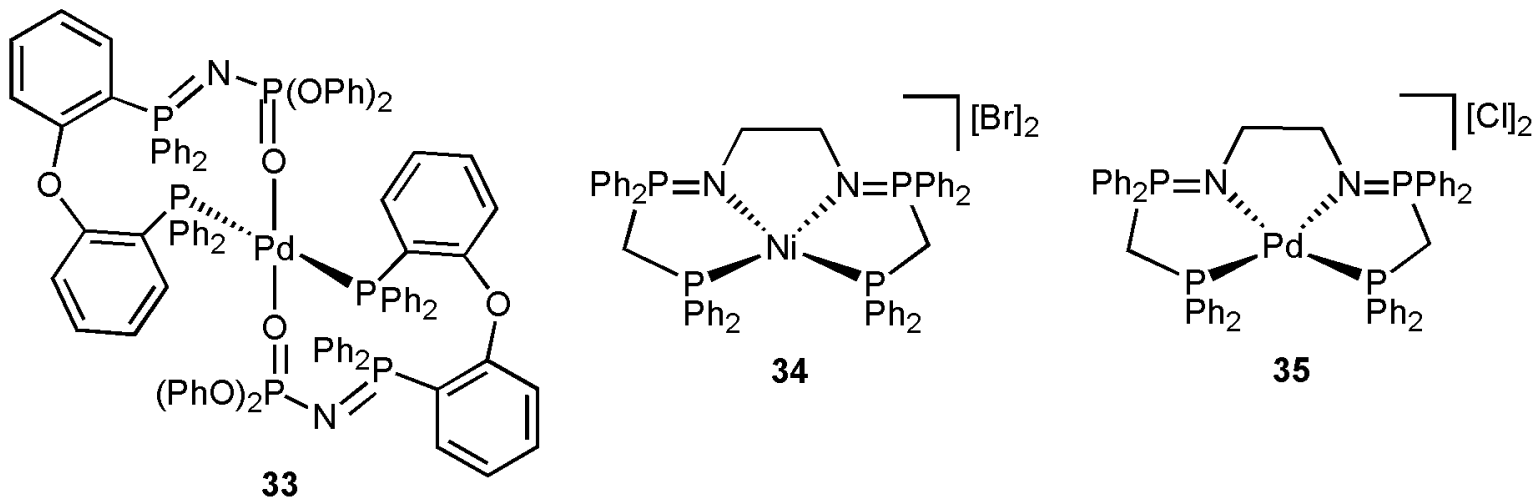

Figure 10. Structures of the palladium and nickel complexes 33-35.

Interestingly, the $\operatorname{Pd}(0)$ complex 33 showed an excellent activity at very low catalyst concentrations $(0.05 \mathrm{~mol} \%)$ [20]. As shown in Scheme 11, using toluene as solvent and $\mathrm{K}_{3} \mathrm{PO}_{4}$ as base, a variety of aryl bromides cleanly reacted with phenylboronic acid to afford the desired biaryls in high yields. It is also worthy of note that catalyst $\mathbf{3 3}$ exhibited a high tolerance towards both deactivating electron-donating substituents and sterically encumbering ortho-substituents on the aryl bromides. 


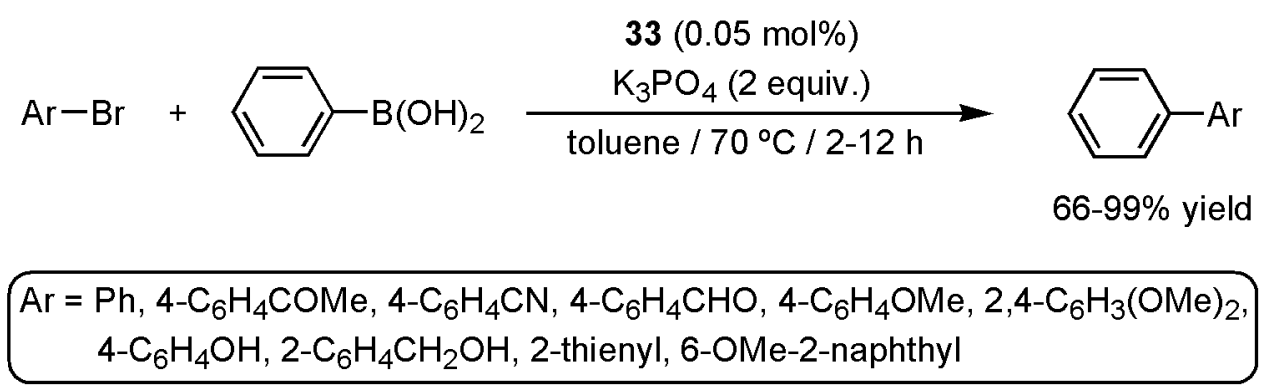

Scheme 11. Suzuki-Miyaura cross-couplings catalyzed by the $\operatorname{Pd}(0)$ complex 33.

Table 3. Suzuki-Miyaura couplings catalyzed by the Ni(II) and Pd(II) complexes 34-35.

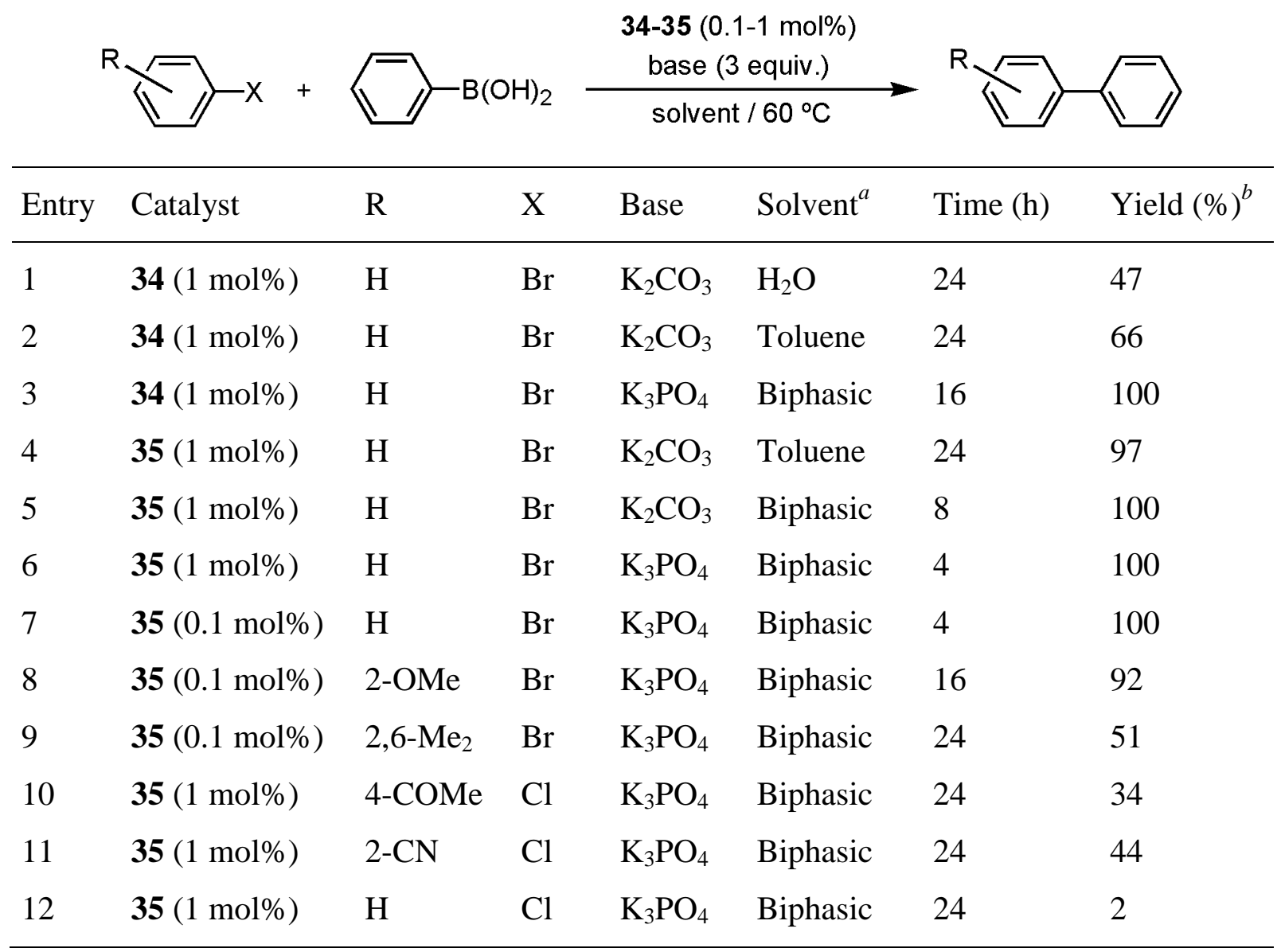

${ }^{a}$ Biphasic solvent $=1: 1 \mathrm{v} / \mathrm{v}$ mixture of toluene/water with $\mathrm{TBABF}_{4}(1.5$ equiv.) as phasetransfer agent. ${ }^{b}$ Determined by GC.

Concerning the $\mathrm{Ni}(\mathrm{II})$ and $\mathrm{Pd}(\mathrm{II})$ derivatives $\mathbf{3 4}$ and $\mathbf{3 5}$, their activity was explored in three different mediums such as toluene, water and a biphasic toluene/water mixture with $\mathrm{TBABF}_{4}\left(\mathrm{TBABF}_{4}=\left[\mathrm{N}\left(n-\mathrm{C}_{4} \mathrm{H}_{9}\right)_{4}\right]\left[\mathrm{BF}_{4}\right]\right)$ as phase-transfer agent [40]. In all of them, complexes 34-35 (1 mol\%) were able to promote the coupling of bromobenzene with phenylboronic acid, leading to biphenyl in moderate to quantitative yields after 4-24 hours at 
$60{ }^{\circ} \mathrm{C}$ (see Table 3). The more satisfactory results were obtained under biphasic conditions (entries 3 and 6), particularly with the palladium(II) complex 35, which catalyzed the coupling reaction to approach completion within 4 hours (entry 6), even with a metal loading of $0.1 \mathrm{~mol} \%$ (entry 7$)$. Complex $35(0.1 \mathrm{~mol} \%)$ proved also effective with deactivated and hindered bromoarenes (entries 8 and 9). However, even with a metal loading of $1 \mathrm{~mol} \%$, the coupling of more challenging chloroarenes proceeded in low yields (entries 10-12), and no improvements were observed by increasing the temperature. It is worthy of note that the use of a biphasic reaction medium allowed an easy separation of the organic products formed and the recycling of $\mathbf{3 5}$ (up to five runs), leading to cumulative TON values of up to 5000 .

The most common way to generate boronic acids is by treatment of the corresponding Grignard reagent with a borate ester [41]. For this reason, the Kumada-Corriu reaction offers a more direct approach to biaryl products when the starting aryl halides tolerate the background reactivity of a Grignard reagent [35,42]. In this context, several nickel(II) complexes containing an iminophosphorane-phosphine backbone have been used to promote Kumada-Corriu C-C couplings (Figure 11).<smiles>ClP1N2C(c3ccccc3)=C[P+](Br)[N+]1(Cl)c1ccccc1P2c1ccccc1</smiles>

$$
\mathrm{Ar}=4-\mathrm{C}_{6} \mathrm{H}_{4} \mathrm{Me}(\mathbf{3 6 a})
$$$$
\mathrm{Ar}=2,6-\mathrm{C}_{6} \mathrm{H}_{3}{ }^{\mathrm{i}} \mathrm{Pr}_{2} \text { (36b) }
$$

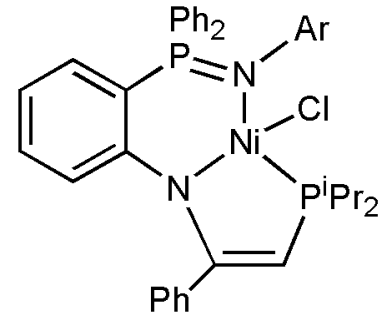

$\mathrm{Ar}=4-\mathrm{C}_{6} \mathrm{H}_{4} \mathrm{Me}(37 \mathrm{a})$

$\mathrm{Ar}=2,6-\mathrm{C}_{6} \mathrm{H}_{3}{ }^{\mathrm{i}} \mathrm{Pr}_{2}$ (37b) $\mathrm{Ar}=\mathrm{Ph}(\mathbf{3 7 c})$<smiles></smiles>

$$
\mathrm{Ar}=4-\mathrm{C}_{6} \mathrm{H}_{4} \mathrm{Me}(\mathbf{3 8 a})
$$$$
\mathrm{Ar}=2,6-\mathrm{C}_{6} \mathrm{H}_{3}{ }^{\mathrm{i}} \mathrm{Pr}_{2} \text { (38b) }
$$<smiles>Cc1ccc(-n2n(Cl)p3n(p2-c2ccccc2)-c2ccccc2C3c2ccccc2)cc1</smiles>

39

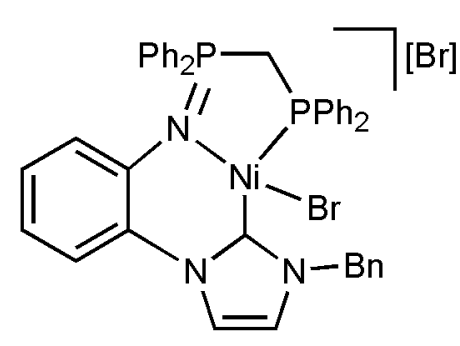

40

Figure 11. Structures of the iminophosphorane-phosphine-based Ni(II) complexes 36-40.

Pioneering work was published in 2007 by Wang and co-workers employing the amido pincer complexes 36a-b and 37a-c [43]. All of them were capable of catalyzing the cross- 
coupling of aryl iodides 4- $\mathrm{RC}_{6} \mathrm{H}_{4} \mathrm{I}(\mathrm{R}=\mathrm{H}, \mathrm{OMe})$ with 4- $\mathrm{MeC}_{6} \mathrm{H}_{4} \mathrm{MgBr}$, in toluene at room temperature, to afford the corresponding biaryls in $91-99 \%$ yield with metal loadings ranging from 0.02 to $0.2 \mathrm{~mol} \%$. Formation of the homocoupling product of the Grignard reagent was not observed in these reactions. Complex 37b was particularly effective since, by using only a $0.02 \mathrm{~mol} \%$ of this catalyst, quantitative conversions were reached after $12 \mathrm{~h}$, even for the deactivated aryl iodide 4- $\mathrm{MeOC}_{6} \mathrm{H}_{4} \mathrm{I}$ (Scheme 12). In addition, 37b proved to be also useful for related couplings of less reactive aryl chlorides. However, in these cases, an increase in the catalyst loading (2.5 mol\%) was needed to achieve high conversions (Scheme 12).

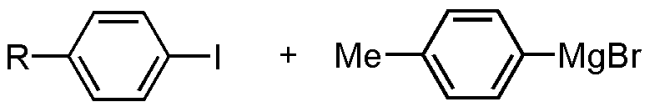

$\mathrm{R}=\mathrm{H}, \mathrm{OMe}$

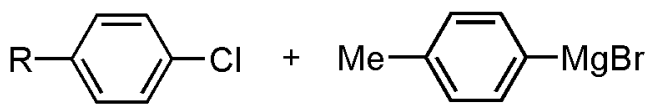

$\mathrm{R}=\mathrm{H}, \mathrm{OMe}$
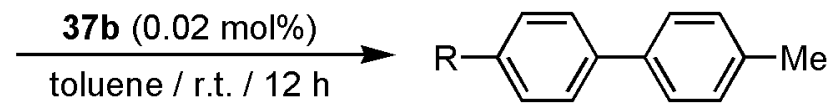

$99 \%$ yield

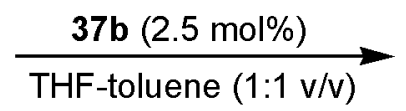

r.t. / 12-24 h

Scheme 12. Kumada-Corriu C-C couplings catalyzed by the Ni(II) complex $\mathbf{3 7 b}$.

These results were subsequently improved by Wang's group using as catalysts the second-generation $\mathrm{Ni}(\mathrm{II})$-amido pincer complexes 38a-b and 39 (see Figure 11), which were able to promote the coupling of $4-\mathrm{MeOC}_{6} \mathrm{H}_{4} \mathrm{I}$ with $4-\mathrm{MeC}_{6} \mathrm{H}_{4} \mathrm{MgBr}$ with metal loadings of $0.005 \mathrm{~mol} \%$ (up to $97 \%$ yield after $12 \mathrm{~h}$ in toluene at room temperature) [44]. However, for the cross-coupling reaction of aryl chlorides, an increase to $2 \mathrm{~mol} \%$ of the catalyst was still needed to generate the biaryl products in high yields. More recently, the $\mathrm{Ni}$ (II) complex $\mathbf{4 0}$, featuring an iminophosphorane-phosphine ligand functionalized with a $N$-heterocyclic carbene (NHC) donor unit, was also evaluated by Wang and co-workers in the Kumada reaction of aryl chlorides. Although active, its effectiveness was comparatively lower than those shown by the amido derivatives 36-39 [45]. On the other hand, the ability of $\mathbf{4 0}$ to promote Negishi-type [46] cross-coupling reactions was also briefly demonstrated (Scheme 13) [45]. However, we must note that, for this particular transformation, related NHC-Ni(II) complexes containing bis(iminophosphorane) backbones proved to be much more active (up to $96 \%$ yield after $16 \mathrm{~h}$ using a Ni loading of only $0.05 \mathrm{~mol} \%$ ). 


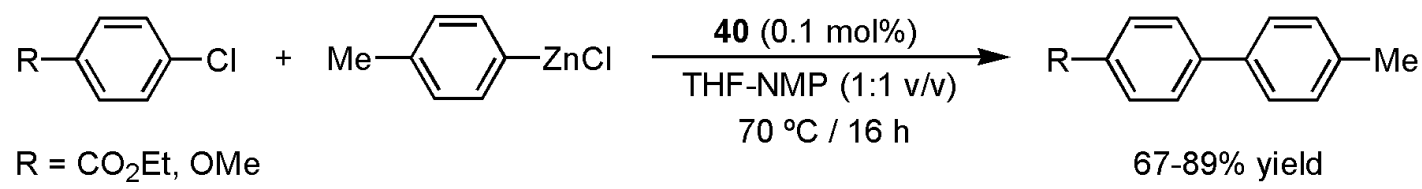

Scheme 13. Negishi reactions catalyzed by the Ni(II) complex $\mathbf{4 0 .}$

\section{Oligomerization and cyclopropanation of olefins}

Oligomerization of ethylene has been of significant interest to both academic and industrial chemists for many years, because the linear $\alpha$-olefins formed in these reactions are extremely useful chemicals for a large range of industrial and consumer products [47]. Latetransition-metal complexes have demonstrated a great potential as catalysts for ethylene oligomerization. Although for a time it was considered that the top had been reached with the nickel derivatives $\left[\mathrm{NiPh}\left(\mathrm{P}^{\wedge} \mathrm{O}\right) \mathrm{L}\right]\left(\mathrm{L}=\right.$ tertiary phosphine; $\mathrm{P}^{\wedge} \mathrm{O}=$ chelating phosphinoenolate ligand) used in the Shell Higher Olefin Process (SHOP) [48], recent interest involving new ligands design has shown that advancements in activity and selectivity are still attainable. In this context, several $\mathrm{Ni}$ (II) and $\mathrm{Co}(\mathrm{II})$ complexes containing iminophosphorane-phosphine ligands have been explored as catalysts in the oligomerization of ethylene (see Figure 12) [49].

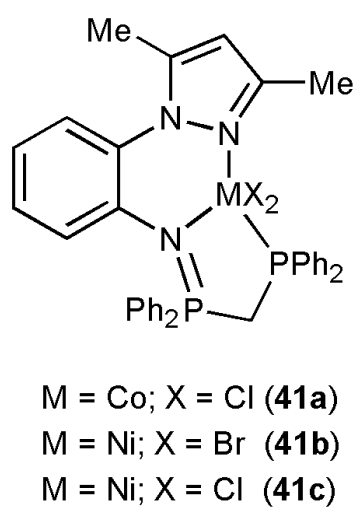<smiles>[R]N1[P+](Br)(Br)CPP1(Br)(Br)[Pb]</smiles>

$$
\begin{aligned}
& \mathrm{R}=\mathrm{CH}_{2}{ }^{\mathrm{t}} \mathrm{Bu}(\mathbf{4 2 a}) \\
& \mathrm{R}=\mathrm{CH}_{2}-4-\mathrm{C}_{6} \mathrm{H}_{4} \mathrm{OMe}(\mathbf{4 2 b}) \\
& \mathrm{R}=\mathrm{Ph}(\mathbf{4 2} \mathrm{c})
\end{aligned}
$$<smiles>[R][R]1c2ccccc2P([N+](Br)(Br)Br)N1[R2]</smiles>

$\mathrm{R}^{\prime}=\mathrm{Ph} ; \mathrm{R}=\mathrm{CH}_{2}{ }^{\mathrm{t}} \mathrm{Bu}(\mathbf{4 3 a})$

$\mathrm{R}^{\prime}=\mathrm{Ph} ; \mathrm{R}={ }^{\mathrm{i}} \operatorname{Pr}(\mathbf{4 3 b})$

$\mathrm{R}^{\prime}=\mathrm{Ph} ; \mathrm{R}={ }^{\mathrm{t}} \mathrm{Bu}(\mathbf{4 3 \mathrm { c }})$

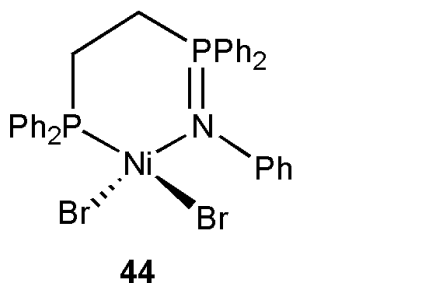

$\mathrm{R}^{\prime}={ }^{\mathrm{i}} \mathrm{Pr} ; \mathrm{R}={ }^{\mathrm{t}} \mathrm{Bu}(\mathbf{4 3 d})$

44

Figure 12. Structures of the iminophosphorane-phosphine-based Ni(II) and Co(II) complexes 41-44.

Concerning complexes 41a-c, the most relevant results obtained by Z.-X. Wang and co-workers are collected in Table 4 [50]. It was first observed that the catalytic activity of these species is strongly affected by the nature of the alkylaluminium activator employed. 
Thus, while the cobalt complex 41a was found to be inoperative in the presence of $\mathrm{Et}_{2} \mathrm{AlCl}$, it showed a modest activity when a large excess of MAO (methylaluminoxane) or MMAO (modified methylaluminoxane) were employed as co-catalysts (entries 1 and 2). The reaction performed with MMAO merits to be highlighted since it showed an excellent selectivity towards the formation of $\mathrm{C}_{4}$ species. In contrast to 41a, under the same experimental conditions (in toluene at $20^{\circ} \mathrm{C}$ under 1 atm of ethylene), the $\mathrm{Ni}$ complexes $\mathbf{4 1 b}$-c proved to be active in the presence of $\mathrm{Et}_{2} \mathrm{AlCl}$ (entries 3-6 and 10), producing mixtures of butenes $\left(\mathrm{C}_{4}\right)$ and hexenes $\left(\mathrm{C}_{6}\right)$. The quantity of $\mathrm{Et}_{2} \mathrm{AlCl}$ employed affected the outcome of the reaction. Thus, as exemplified with $\mathbf{4 1 b}$, the increase of the Al/Ni molar ratio from 50:1 to 300:1 led to an improvement in its catalytic activity (entries 3-5), but further increase of the $\mathrm{Al} / \mathrm{Ni}$ ratio resulted counterproductive (entry 6). The effect of the temperature on the activity of $\mathbf{4 1 b}$ was also studied (entries 7-9), the best results in terms of activity being reached at $40{ }^{\circ} \mathrm{C}(3.54 \mathrm{x}$ $10^{6} \mathrm{~g} \cdot \mathrm{mol}^{-1} \cdot \mathrm{h}^{-1}$; entry 8 ). At this temperature, an improvement of the activity could be achieved by increasing the ethylene pressure $\left(8.52 \times 10^{6} \mathrm{~g} \cdot \mathrm{mol}^{-1} \cdot \mathrm{h}^{-1}\right.$; entry 11$)$.

Table 4. Ethylene polymerization with the $\mathrm{Co}(\mathrm{II})$ and $\mathrm{Ni}(\mathrm{II})$ complexes 41a-c. $^{a}$

\begin{tabular}{llllllll}
\hline Entry & Catalyst & Co-Cat. & $\mathrm{Al} / \mathrm{M}$ & $\mathrm{T}\left({ }^{\circ} \mathrm{C}\right)$ & Activity $^{b}$ & $\mathrm{C}_{4}(\%)^{c}$ & $\mathrm{C}_{6}(\%)^{c}$ \\
\hline 1 & $\mathbf{4 1 a}$ & $\mathrm{MAO}$ & 2400 & 20 & 0.07 & 22.6 & 77.4 \\
2 & $\mathbf{4 1 a}$ & $\mathrm{MMAO}$ & 2000 & 20 & 0.34 & $>99$ & -- \\
3 & $\mathbf{4 1 b}$ & $\mathrm{Et}_{2} \mathrm{AlCl}$ & 50 & 20 & 1.80 & 76.6 & 23.4 \\
4 & $\mathbf{4 1 b}$ & $\mathrm{Et}_{2} \mathrm{AlCl}$ & 200 & 20 & 2.12 & 78.8 & 21.2 \\
5 & $\mathbf{4 1 b}$ & $\mathrm{Et}_{2} \mathrm{AlCl}$ & 300 & 20 & 2.97 & 61.0 & 39.0 \\
6 & $\mathbf{4 1 b}$ & $\mathrm{Et}_{2} \mathrm{AlCl}$ & 500 & 20 & 2.63 & 57.4 & 42.6 \\
7 & $\mathbf{4 1 b}$ & $\mathrm{Et}_{2} \mathrm{AlCl}$ & 300 & 0 & 2.38 & 80.5 & 19.5 \\
8 & $\mathbf{4 1 b}$ & $\mathrm{Et}_{2} \mathrm{AlCl}$ & 300 & 40 & 3.54 & 72.2 & 27.8 \\
9 & $\mathbf{4 1 b}$ & $\mathrm{Et}_{2} \mathrm{AlCl}$ & 300 & 60 & 1.07 & 68.0 & 32.0 \\
10 & $\mathbf{4 1 c}$ & $\mathrm{Et}_{2} \mathrm{AlCl}$ & 300 & 20 & 2.85 & 70.5 & 29.5 \\
$11^{d}$ & $\mathbf{4 1 b}$ & $\mathrm{Et}_{2} \mathrm{AlCl}$ & 300 & 40 & 8.52 & 76.2 & 23.8 \\
\hline
\end{tabular}

${ }^{a}$ Conditions: $5 \mu \mathrm{mol}$ of catalyst, $30 \mathrm{~mL}$ of toluene and $1 \mathrm{~atm}$ of ethylene. ${ }^{b} 10^{6} \mathrm{~g} \cdot \mathrm{mol}^{-1} \cdot \mathrm{h}^{-1} \cdot{ }^{c}$ Weight percent determined by GC analysis. ${ }^{d}$ Reaction conducted at $10 \mathrm{~atm}$ of ethylene. 
In a subsequent study Le Floch and co-workers reported on the use of the $\mathrm{Ni}(\mathrm{II})$ complexes 42-44 (Figure 12) for ethylene oligomerization [51]. Performing the catalytic reactions in toluene at $45{ }^{\circ} \mathrm{C}$ under 30 atm of ethylene, and in the presence of MAO $(\mathrm{Al} / \mathrm{Ni}$ molar ratio of 300), all of them proved to be highly active (TOF values in the range 21.1$106.5 \times 10^{3}$ mol ethylene consumed per mol of Ni per hour) and remarkably selective giving mainly butenes (between 88.9 and $96.7 \%$ with up to $85 \%$ of 1-butene) and few hexenes (between 3.6 and 10\%). Such selectivities compare favourably with the performances of the best systems previously reported in the literature for ethylene dimerization [47]. In general, complexes 43a-d, which feature a rigid six-membered metallacycle, were more active than 42a-c and 44, although this increased reactivity was accompanied with a decrease of the selectivity in 1-butene. The fundamental role played by the $P, N$-donor iminophosphoranephosphine ligands on the selectivity of the process towards the dimerization products was evidenced through density functional theory (DFT) calculations, which clearly indicated that the presence of two electronically different binding sites on the ligand disfavour the coordination of a third ethylene molecule during the catalytic cycle [51b].

Table 5. Ru-catalyzed asymmetric cyclopropanation of styrene.
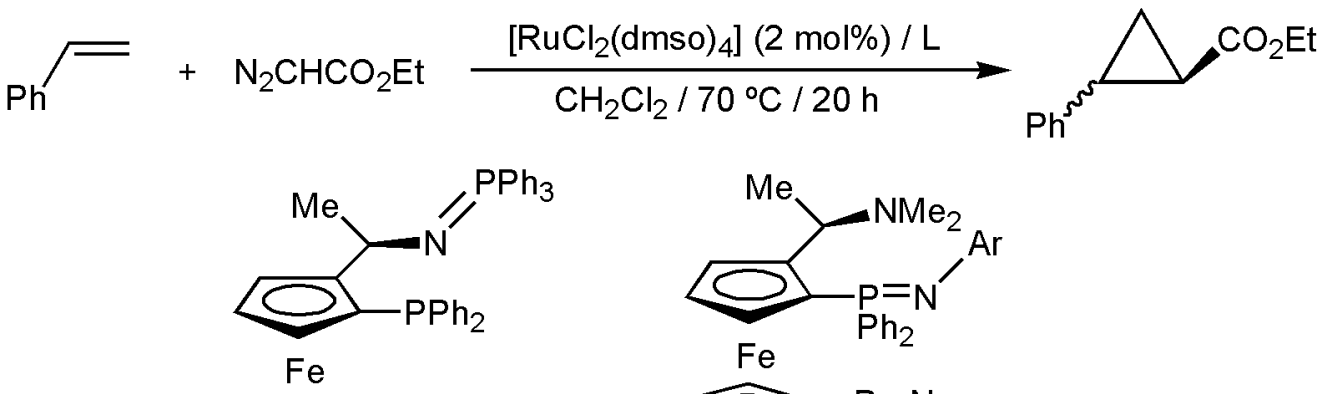

$\mathrm{Fe}$

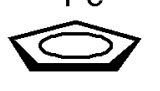

$5 a$

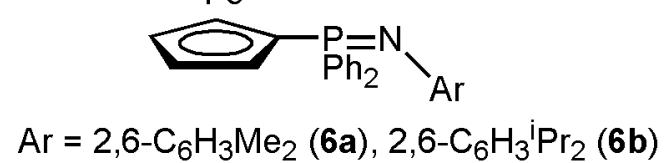

\begin{tabular}{llllll}
\hline Entry & $\mathrm{L}$ & $\mathrm{Ru} / \mathrm{L}$ & ${\text { Yield }(\%)^{a}}$ & $d r(\%)\left(\right.$ trans/cis $^{a}$ & ee $(\%)(\text { trans/cis })^{a}$ \\
\hline 1 & $\mathbf{5 a}$ & $1: 1$ & 79 & $53: 47$ & $97: 99$ \\
2 & $\mathbf{5 a}$ & $1: 2$ & 60 & $30: 70$ & $99: 99$ \\
3 & $\mathbf{6 a}$ & $1: 1$ & 64 & $15: 85$ & $01: 99$ \\
4 & $\mathbf{6 a}$ & $1: 2$ & 97 & $70: 30$ & $99: 72$ \\
5 & $\mathbf{6 b}$ & $1: 1$ & 74 & $88: 12$ & $33: 31$ \\
6 & $\mathbf{6 b}$ & $1: 2$ & 74 & $09: 91$ & $99: 91$ \\
\hline
\end{tabular}

\footnotetext{
${ }^{a}$ Determined by GC.
} 
On a different plane, the catalytic asymmetric cyclopropanation of olefins is a topic of considerable interest due to the great relevance of the chiral cyclopropane motif in synthetic organic chemistry [52]. Kim and co-workers have demonstrated the potential of the optically active ferrocenyl-based ligand $\mathbf{5 a}$ in such a transformation, by performing the rutheniumcatalyzed cyclopropanation of styrene with ethyl diazoacetate (EDA) [53]. As shown in Table 5, using a metal-to-ligand ratio of 1:1, an almost equimolar amount of both cis and trans isomers were formed with remarkably high enatioselectivities (up to $99 \%$ ee; entry 1). An increase in the ligand-to-metal ratio to 1:2 allowed to improve the diastereoselectivity of the process in favour of the cis isomer, albeit with a slight erosion in the reaction yield (entry 2). The related ferrocenyl-bis(iminophosphorane) ligands $\mathbf{6 a - b}$ were also employed in the reaction (entries 4-6). In general, the enantiomeric excesses reached with these $N, N$-donor ligands were lower in comparison with those of $\mathbf{5 a}$ but the diastereomeric ratios could be significantly improved, particularly with $\mathbf{6 b}$ which showed an impressive reversal in diasteroselectivity as a function of the metal-to-ligand ratio (entries 5-6).

\section{Other catalytic transformations}

Transition metal-catalyzed heteroannulation reactions of suitable acyclic precursors are probably the most appealing and innovative strategies presently available to access furans since they usually proceed with complete atom-economy [54]. In this context, several palladium(II) complexes $\mathbf{4 5 - 4 7 a - b}$, derived from the $N$-phosphorylated iminophosphoranephosphine ligands $\mathrm{Ph}_{2} \mathrm{PCH}_{2} \mathrm{P}\left\{=\mathrm{NP}(=\mathrm{O})(\mathrm{OR})_{2}\right\} \mathrm{Ph}_{2}(\mathrm{R}=\mathrm{Et}, \mathrm{Ph})$, have proven to be active catalysts for the cycloisomerization of (Z)-3-methylpent-2-en-4-yn-1-ol into 2,3dimethylfuran (Scheme 14) [55].

Reactions proceeded in the absence of any solvent under remarkably mild conditions (room temperature), with the chelate complexes $45 \mathbf{a}-\mathbf{b}$ and $\mathbf{4 6} \mathbf{a}-\mathbf{b}$ showing much better performances than those of the acyclic derivatives 47a-b (TOF values $=52-124 v s \quad 20-21 \mathrm{~h}^{-1}$ ). In particular, the dicationic complex $\left[\mathrm{Pd}\left(\mathrm{Ph}_{2} \mathrm{PCH}_{2} \mathrm{P}\left\{=\mathrm{NP}(=\mathrm{O})(\mathrm{OPh})_{2}\right\} \mathrm{Ph}_{2}\right)_{2}\right]\left[\mathrm{SbF}_{6}\right]_{2}(\mathbf{4 6 b})$ was found to be the most effective, yielding 2,3-dimethylfuran in almost quantitative yield after only $4 \mathrm{~h}\left(\mathrm{TOF}=124 \mathrm{~h}^{-1}\right)$. It is well-established that this type of cycloisomerization reactions proceeds via initial $\pi$-coordination of the enynol $\mathrm{C} \equiv \mathrm{C}$ bond to the metal, and subsequent intramolecular nucleophilic attack of the pendant $\mathrm{OH}$ group on the activated alkyne unit [54]. Consequently, the higher catalytic activity shown by 45-46a-b when 
compared to $47 \mathbf{a}-\mathbf{b}$ was ascribed to the more effective generation of a vacant coordination site by chelate ring opening $v s$ chloride dissociation, thus representing a good example of the utility of the hemilability concept in homogeneous catalysis. It is also important to note that complexes 45-46a-b were found to be much more active than $\mathrm{K}_{2}\left[\mathrm{PdI}_{4}\right]$, the most commonly used palladium-based catalyst for this type of heteroannulation reactions [56].

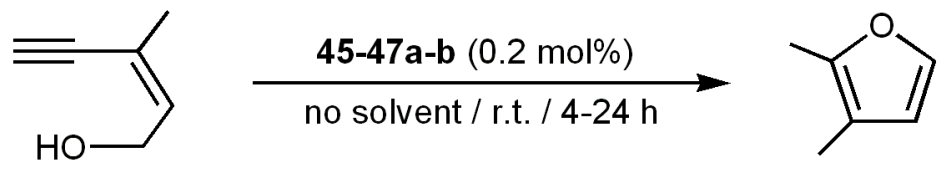

\section{3-99\% yield}
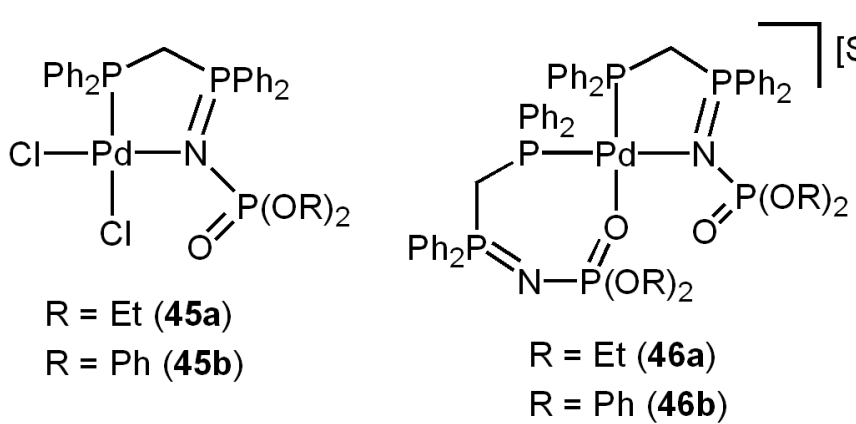

$\left[\mathrm{SbF}_{6}\right]_{2}$

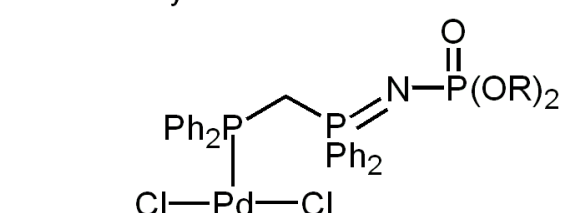<smiles>[O-][P+](=NP=NP)PCP(Cl)P(Cl)Cl</smiles>

Scheme 14. Palladium-catalyzed 2,3-dimethylfuran formation.

The Meyer-Schuster and Rupe rearrangements, i.e. the conversion of propargylic alcohols into the corresponding $\alpha, \beta$-unsaturated carbonyl isomers by formal 1,3- or 1,2-shift of the hydroxyl moiety, represent straightforward routes to these synthetically useful intermediates due to the easy access of the starting materials [57]. The most recent and convenient protocols to promote these isomerization reactions are based on the use of metal catalysts since they are more selective, and operate under milder reaction conditions, when compared to the classical methods involving strong Brønsted acids. In this context, it has been very recently demonstrated that the cationic rhenium(I) complex 48 , containing the $N$ thiophosphorylated iminophosphorane-phosphine ligand $\mathrm{Ph}_{2} \mathrm{PCH}_{2} \mathrm{P}\left\{=\mathrm{NP}(=\mathrm{S})(\mathrm{OPh})_{2}\right\} \mathrm{Ph}_{2}$ coordinated in a tridentate $\kappa^{3}-(P, N, S)$ manner, is a highly efficient catalyst to promote the chemoselective transformation of terminal propargylic alcohols into enals (Meyer-Schuster rearrangement) or methyl-enones (Rupe rearrangement) depending on the substitution pattern of the starting materials (representative examples are shown in Scheme 15) [58]. Reactions, performed with $5 \mathrm{~mol} \%$ of this complex in tetrahydrofuran at $80{ }^{\circ} \mathrm{C}$ (under $\mathrm{MW}$ irradiation), delivered the final carbonyl compounds in excellent yields (85-94\%) and short times (from $5 \mathrm{~min}$ to $4.5 \mathrm{~h}$ ). It is also worthy of note that the use of the ionic liquid 
$[\mathrm{BMIM}]\left[\mathrm{PF}_{6}\right] \quad(\mathrm{BMIM}=1$-butyl-3-methylimidazolium) as solvent, instead of tetrahydrofuran, allowed the effective recycling of the rhenium(I) catalyst $\mathbf{4 8}$ (up to 10 consecutive runs) after the selective extraction of the final reaction products with diethyl ether.<smiles>[R]C([R])(O)C#C</smiles>

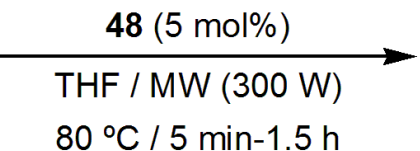
$80^{\circ} \mathrm{C} / 5 \mathrm{~min}-1.5 \mathrm{~h}$

$\mathrm{R}^{1}=\mathrm{R}^{2}=\mathrm{Ph}, 4-\mathrm{C}_{6} \mathrm{H}_{4} \mathrm{Me}, 4-\mathrm{C}_{6} \mathrm{H}_{4} \mathrm{OMe}, 4-\mathrm{C}_{6} \mathrm{H}_{4} \mathrm{~F}, 4-\mathrm{C}_{6} \mathrm{H}_{4} \mathrm{Cl}$ $\mathrm{R}^{1}=\mathrm{H} ; \mathrm{R}^{2}=\mathrm{Ph}, 4-\mathrm{C}_{6} \mathrm{H}_{4} \mathrm{Me}, 4-\mathrm{C}_{6} \mathrm{H}_{4} \mathrm{Cl}$, 1-Naphthyl<smiles>[R]C([R])=CC=O</smiles>
85-94\% yield

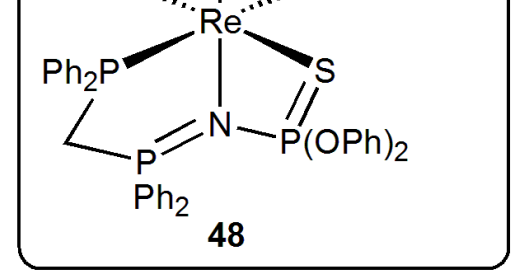

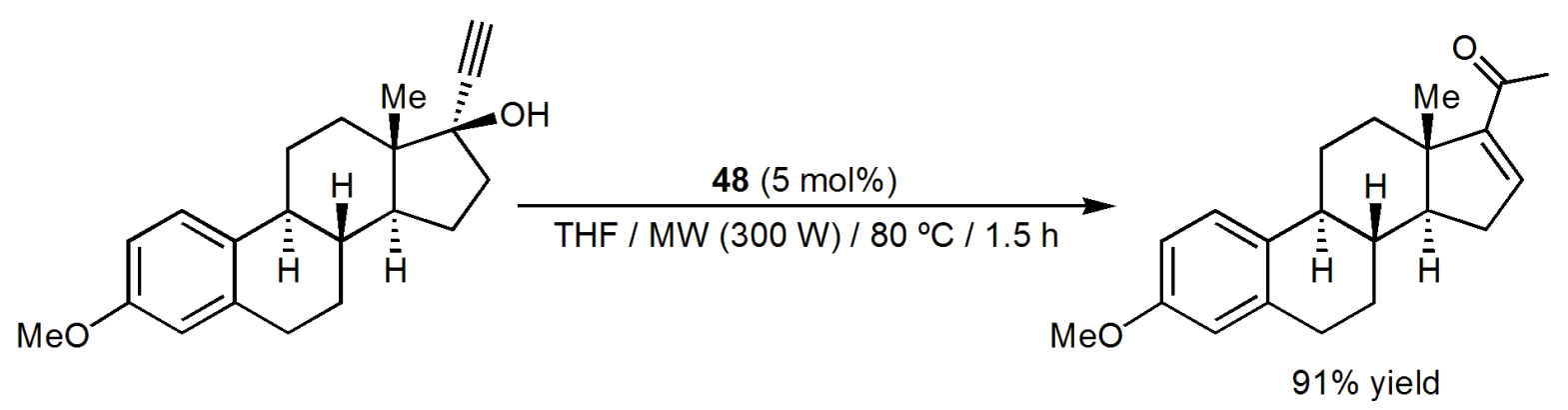<smiles>C#C[C@]1(O)CC[C@H]2[C@@H]3CCC4=CC(=O)CC[C@]4(C)[C@H]3CC[C@]21C</smiles><smiles>CC(=O)C1=CC[C@H]2[C@H]3CCC4=CC(=O)CC[C@]4(C)[C@H]3CC[C@]12C(C)C</smiles>

Scheme 15. Meyer-Schuster and Rupe rearrangements catalyzed by the Re(I) complex 48.

When associated with $\mathrm{AgSbF}_{6}$, the regioisomeric arene-ruthenium(II) complexes 49a-b and 50a-b, containing enantiopure $\kappa^{1}-(P)$-coordinated iminophosphorane-phosphine ligands derived from $\left(S_{\mathrm{P}} S_{\mathrm{C}}\right)$-2-diphenylphosphino-1-phenyl-phospholane, were found to act as Lewis acid catalysts in the Diels-Alder cycloaddition of acrolein with cyclopentadiene (Scheme 16) [59]. However, only moderate activities and low diastereo- and enantioselectivities were observed (up to 83:17 endo/exo ratio (50a) with up to $48 \%$ ee (49a) for the major endo cycloadduct) [60]. 


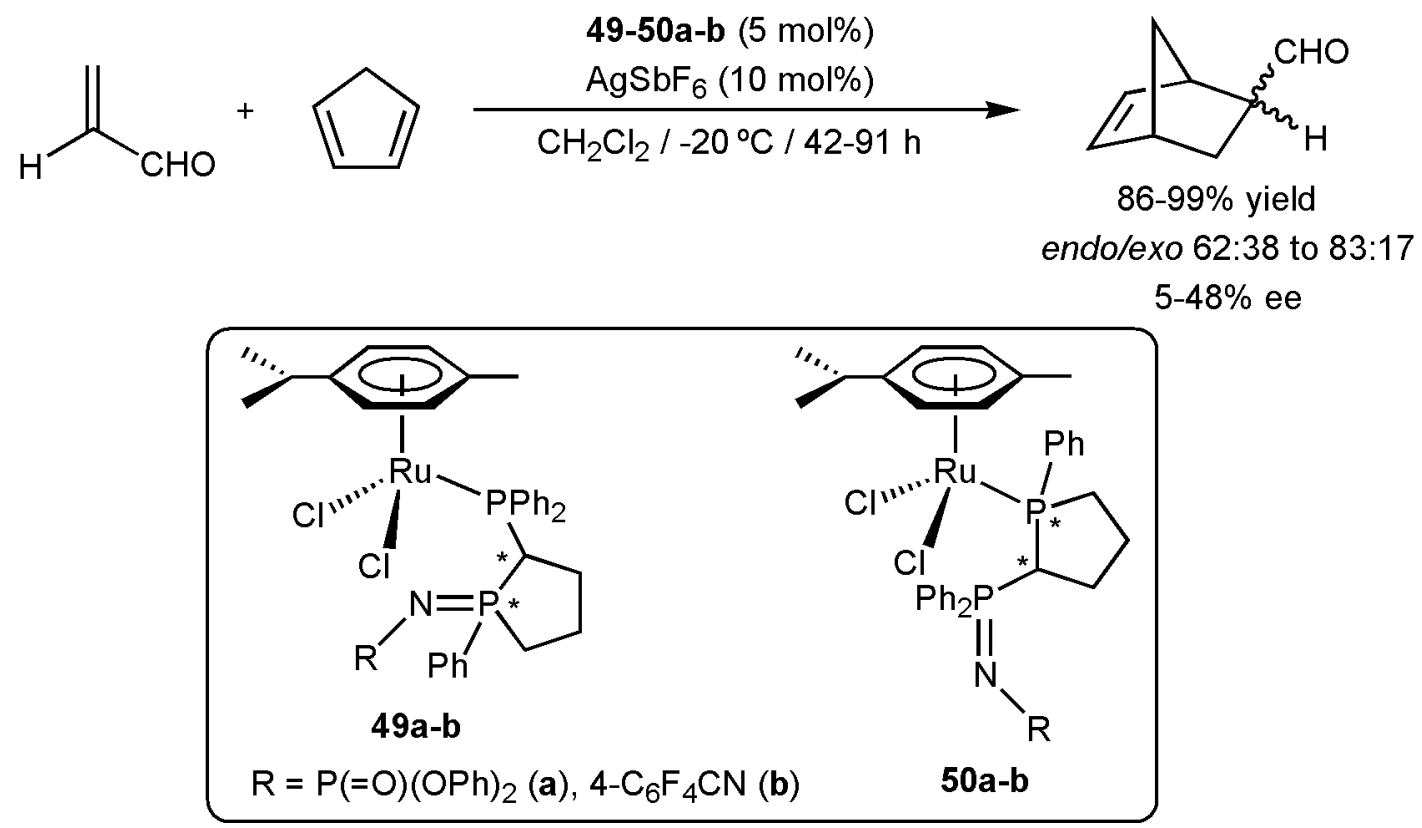

Scheme 16. Diels-Alder reaction of acrolein with cyclopentadiene catalyzed by complexes 49-50a-b.

Much better enantiomeric excesses were described by Kim and co-workers in the copper-catalyzed allylic oxidation of cyclic alkenes by tert-butyl perbenzoate (KharashSosnovsky reaction [61]) using the (iminophosphoranyl)ferrocenes $\mathbf{4 a}, \mathbf{5 a}$ and $\mathbf{6 a - b}$ (Figure 4) as chiral inductors [62]. Best results in terms of both reaction yields (up to 85\%) and enantioselectivities (up to $98 \%$ ) were achieved with the $P, N$-donor iminophosphoranephosphine ligand 5a (Scheme 17), the ee values reached being among the highest reported in the literature for this transformation [63]. The allylic oxidation of the less reactive substrate 1,5-cyclooctadiene, under the same experimental conditions, was also studied by the authors, obtaining extraordinary results with an almost perfect enantioselectivity and conversion (Scheme 17). This result is remarkable since only a few reports are available for the allylic oxidation of this substrate [63].

The ferrocenyl ligands $\mathbf{4 a - b}, \mathbf{5 a}-\mathbf{b}$ and $\mathbf{6 a - c}$ were also applied in a series of $\mathrm{Rh}(\mathrm{I})$ - and Pd(II)-catalyzed asymmetric allylic alkylation reactions (Scheme 18) [64]. Concerning the $\mathrm{Rh}(\mathrm{I})$-catalyzed allylic alkylation of cinnamyl acetate with dimethyl malonate, regardless of the ligand employed, high regiocontrol in favour of the linear achiral isomer and relatively high enantiomeric excesses (up to $91 \%$ ee) for the minor branched isomer were observed. In contrast, very modest enantiomeric excesses were reached in the $\mathrm{Pd}(\mathrm{II})$-catalyzed alkylation of 1,3-diphenylallyl acetate with dimethyl malonate (up to $74 \% e e$ ). 


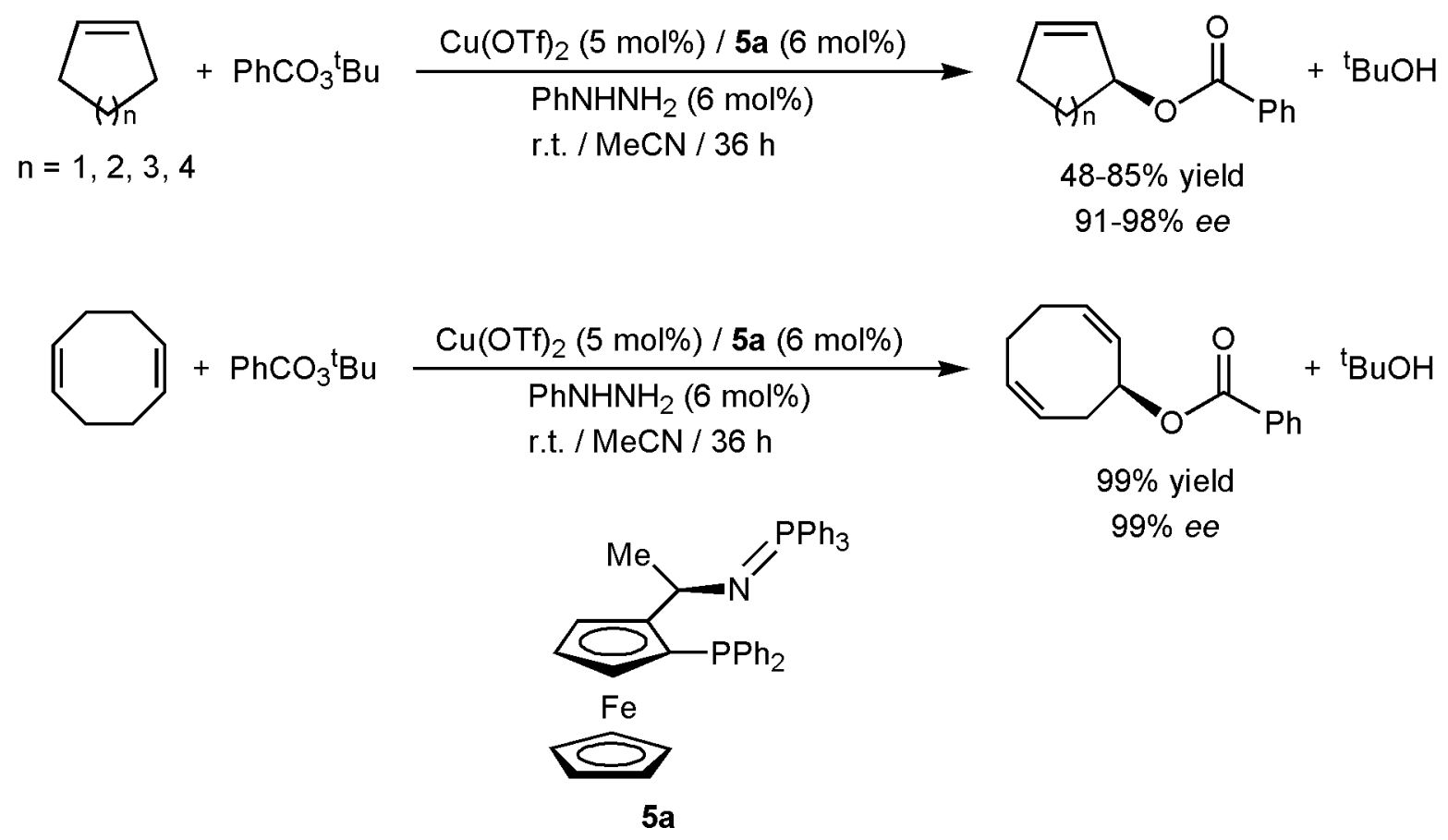

Scheme 17. Cu-catalyzed asymmetric allylic oxidation of cyclic alkenes.

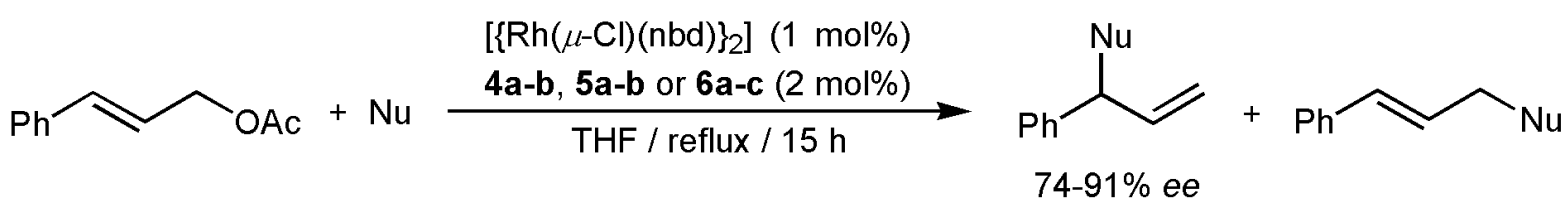

$12-70 \%$ yield (b/l ratio: from $11: 89$ to $18: 82$ )
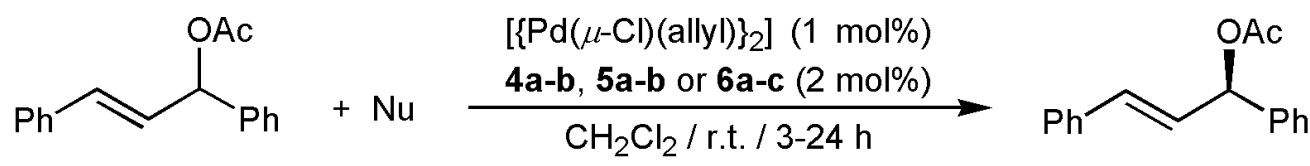

$\mathrm{Nu}=\mathrm{NaCH}\left(\mathrm{CO}_{2} \mathrm{Et}\right)_{2}$

$54-97 \%$ yield; $25-74 \%$ ee

Scheme 18. Rh(I)- and Pd(II)-catalyzed allylic alkylations using (iminophosphoranyl)ferrocene ligands.

Finally, we must also mention that, in the context of a patented work [65], Cavell and co-workers have also developed different catalytic systems, based on the combination of the $\mathrm{Rh}(\mathrm{I})$ dimer $\left[\left\{\mathrm{Rh}(\mu-\mathrm{Cl})(\mathrm{CO})_{2}\right\}_{2}\right]$ and iminophosphorane-phosphines of general composition $\mathrm{Ph}_{2} \mathrm{P}-\left(\mathrm{CH}_{2}\right)_{\mathrm{n}}-\mathrm{P}(=\mathrm{NR}) \mathrm{Ph}_{2}\left(\mathrm{n}=1-5 ; \mathrm{R}=\mathrm{SiMe}_{3}, 4-\mathrm{C}_{6} \mathrm{~F}_{4} \mathrm{CN}, 4-\mathrm{C}_{5} \mathrm{~F}_{4} \mathrm{~N}\right)$, for the carbonylation of methanol to acetic acid. TON values up to 730 could be reached performing the catalytic reactions at $80{ }^{\circ} \mathrm{C}$ with a $\mathrm{CO}$ pressure of $2.8 \mathrm{~atm}$.

\section{Conclusions}


In this review article we have presented a comprehensive account of the applications of mixed ligands featuring both phosphine and iminophosphorane donor groups in homogeneous catalysis. As the reader will have noticed, a number of structurally very diverse iminophosphorane-phosphine ligands have been employed in the last years for the development of catalytic systems based on late-transition metals, mainly of Groups 7-11. With them, relevant transformations in synthetic organic chemistry, such as hydrogenations, C-C couplings, rearrangements or heteroannulation reactions, have been studied and satisfactory results have been in most cases obtained. The almost infinite combinations of these two functionalities within the structure of a ligand that one can imagine, e.g. joined through different organic linkers, by inclusion of additional coordinating groups, etc., will certainly lead in the near future to the design of new metal complexes exploitable in catalysis. We hope that this article will serve as inspiration for future work in this promising research field, which is clearly open with many opportunities for the new discoveries.

\section{Acknowledgements}

This work was supported by the Spanish MINECO (projects CTQ2010-14796/BQU and CSD2007-00006). J.G.-A. and S.E.G.-G. thank MINECO and the European Social Fund for the award of "Ramón y Cajal" contracts.

\section{References}

[1] H. Staudinger, J. Meyer, Helv. Chim. Acta 2 (1919) 635-646.

[2] A.W. Johnson, in: Ylides and Imines of Phosphorus, Wiley-Interscience, New York, 1993.

[3] See, for example: (a) P.M. Fresneda, P. Molina, Synlett (2004) 1-17; (b) S. Eguchi, ARKIVOC 2 (2005) 98-119; (c) F. Palacios, C. Alonso, D. Aparicio, G. Rubiales, J.M. de los Santos, Tetrahedron 63 (2006) 523-575; (d) M.-W. Ding, G.-F. Yang, Trends Heterocycl. Chem. 11 (2006) 87-94; (e) G. Hajos, I. Nagy, Curr. Org. Chem. 12 (2008) 39-58; (f) F. Palacios, D. Aparicio, G. Rubiales, C. Alonso, J.M. de los Santos, Curr. Org. Chem. 13 (2009) 810-828; (g) F. Palacios, C. Alonso, D. Aparicio, G. Rubiales, J.M. de los Santos, in: S. Brase, K. Banert (Eds.), Organic Azides, John Wiley \& Sons, Chichester, 2010, pp. 439-467; (h) Q.-Y. Ren, X.-S. Tan, H.-W. He, Curr. Org. Synth. 
8 (2011) 752-763; (i) P. Molina, A. Tárraga, M. Alfonso, Eur. J. Org. Chem. (2011) 4505-4518.

[4] See, for example: (a) I.S. Resck, Quim. Nova 17 (1994) 317-322; (b) P. Ilankumaran, G. Zhang, J.G. Verkade, Heteroatom Chem. 11 (2000) 251-253; (c) Superbases for Organic Synthesis, T. Ishikawa (Ed.), John Wiley \& Sons, Chichester, 2009.

[5] See, for example: (a) H.R. Allcock, in: Chemistry and Applications of Polyphosphazenes, John Wiley \& Sons, New York, 2003; (b) Applicative Aspects of Poly(Organophosphazenes), M. Gleria, R. de Jaeger (Eds.), Nova Science Publishers, New York, 2004; (c) Synthesis and Characterization of Poly(Organophosphazenes), M. Gleria, R. de Jaeger (Eds.), Nova Science Publishers, New York, 2004; (d) T. Baumgartner, R. Réau, Chem. Rev. 106 (2006) 4681-4727; (e) Polyphosphazenes for Biomedical Applications, A.K. Andrianov (Ed.), John Wiley \& Sons, New York, 2009; (f) V. Blackstone, A.J. Lough, M. Murray, I. Manners, J. Am. Chem. Soc. 131 (2009) 3658-3667.

[6] For reviews on the Staudinger reaction, see: (a) Y.G. Gololobov, I.N. Zhmurova, L.F. Kasukhin, Tetrahedron 37 (1981) 437-472; (b) Y.G. Gololobov, L.F. Kasukhin, Tetrahedron 48 (1992) 1353-1406; (c) S.S. van Berkel, M.B. van Eldijk, J.C.M. van Hest, Angew. Chem. Int. Ed. 50 (2011) 8806-8827.

[7] A.V. Kirsanov, Isv. Akad. Nauk. SSSR, Ser. Khim. (1950) 426-437.

[8] Representative examples of this reaction can be found in: (a) T. Rodima, V. Mäemets, I. Koppel, J. Chem. Soc., Perkin Trans 1 (2000) 2637-2644; (b) I. Kaljurand, T. Rodima, A. Pihl, V. Mäemets, I. Leito, I.A. Koppel, M. Mishima, J. Org. Chem. 68 (2003) 9988-9993; (c) M. Demange, L. Boubekeur, A. Auffrant, N. Mézailles, L. Ricard, X. Le Goff, P. Le Floch, New J. Chem. 30 (2006) 1745-1754; (d) T. Saplinova, C. Lehnert, U. Boehme, J. Wagler, E. Kroke, New J. Chem. 34 (2010) 1893-1908.

[9] See, for example: (a) E.W. Abel, S.A. Mucklejohn, Phosphorus Sulfur Relat. Elem. 9 (1981) 235-266 and references cited therein; (b) J. Vicente, A. Arcas, D. Bautista, M.C. Ramírez de Arellano, Organometallics 17 (1998) 4544-4550 and references cited therein; (c) A. Steiner, S. Zacchini, P.I. Richards, Coord. Chem. Rev. 227 (2002) 193216.

[10] M. Fukui, K. Itoh, Y. Ishii, Bull. Chem. Soc. Jpn. 48 (1975) 2044-2046.

[11] See, for example: (a) L. Beaufort, F. Benvenuti, L. Delaude, A.F. Noels, J. Mol. Catal. A: Chem. 283 (2008) 77-82; (b) O. Alhomaidan, G. Bai, D.W. Stephan, Organometallics 27 (2008) 6343-6352; (c) E. Martinez-Arripe, F. Jean-Baptiste-dit- 
Dominique, A. Auffrant, X.-F. Le Goff, J. Thuilliez, F. Nief, Organometallics 31 (2012) 4854-4861; (d) P.P.M. Hoang, C. Baar, V. Ker, B.M. Shaw, P. Lam, L.D. Henderson, C.A.G. Carter, Y. Jiang, PCT Int. Appl. (2012) WO2012167348; (e) P.P.M. Hoang, C. Baar, P.S. Chisholm, D. Rajesh, PCT Int. Appl. (2013) WO2013026131.

[12] See, for example: (a) A. Buchard, R.H. Platel, A. Auffrant, X.F. Le Goff, P. Le Floch, C.K. Williams, Organometallics 29 (2010) 2892-2900; (b) Z.-A. Ma, Z.-X. Wang, Organometallics 30 (2011) 4364-4373; (c) T.-P.-A. Cao, A. Buchard, X.F. Le Goff, A. Auffrant, C.K. Williams, Inorg. Chem. 51 (2012) 2157-2169; (d) C. Bakewell, T.-P.-A. Cao, N. Long, X.F. Le Goff, A. Auffrant, C.K. Williams, J. Am. Chem. Soc. 134 (2012) 20577-20580; (e) C.A. Wheaton, P.G. Hayes, Catal. Sci. Technol. 2 (2012) 125138; (f) C. Bakewell, T.-P.-A. Cao, X.F. Le Goff, N. Long, A. Auffrant, C.K. Williams, Organometallics 32 (2013) 1475-1483.

[13] (a) J. García-Álvarez, J. Díez, J. Gimeno, Green Chem. 12 (2010) 2127-2130; (b) J. García-Álvarez, J. Díez, C. Vidal, Green Chem. 14 (2012) 3190-3196; (c) J. GarcíaÁlvarez, J. Díez, J. Gimeno, F.J. Suárez, C. Vicent, Eur. J. Inorg. Chem. (2012) 58545863; (d) J. García-Álvarez, J. Díez, C. Vidal, C. Vicent, Inorg. Chem. 52 (2013) 65336542.

[14] For reviews on hemilabile ligands, see: (a) C.S. Slone, D.A Weinberger, C.A. Mirkin, Prog. Inorg. Chem. 48 (1999) 233-350; (b) P. Braunstein, F. Naud, Angew. Chem. Int. Ed. 40 (2001) 680-699; (c) A.D. Burrows, Science Progress 85 (2002) 199-217; (d) P. Braunstein, J. Organomet. Chem. 689 (2004) 3953-3967; (e) S.E. Angell, C.W. Rogers, Y. Zhang, M.O. Wolf, W.E. Jones, Coord. Chem. Rev. 250 (2006) 1829-1841; (f) M. Bassetti, Eur. J. Inorg. Chem. (2006) 4473-4482; (g) F.Y. Kwong, A.S.C. Chan, Synlett (2008) 1440-1448; (h) S. Gu, C. Chen, H. Qiu, W. Chen, Curr. Org. Chem. 15 (2011) 3291-3308; (i) J.I. van der Vlugt, Eur. J. Inorg. Chem. (2012) 363-375.

[15] For overviews on the coordination chemistry of iminophosphorane-phosphines of type $\mathrm{R}_{2} \mathrm{P}-\mathrm{X}-\mathrm{P}\left(=\mathrm{N}^{\prime} \mathrm{R}\right) \mathrm{R}_{2}$ (X = alkyl or aryl chain), see: (a) K.V. Katti, R.G. Cavell, Comments Inorg. Chem. 10 (1990) 53-73; (b) R.G. Cavell, Curr. Sci. 78 (2000) 440451.

[16] Selected iminophosphorane-based catalysts, including examples with iminophosphorane-phosphine ligands, have been recently highlighted in: A. Auffrant, L’Actualité Chimique 359 (2012) 13-19. 
[17] The chemistry of ruthenium complexes with iminophosphorane ligands has been reviewed: V. Cadierno, J. García-Álvarez, in: Ruthenium: Properties, Production and Applications, D.B. Watson (Ed.), Nova Science Publishers, New York, 2011.

[18] See, for example: (a) P.A. Chaloner, M.A. Esteruelas, F. Joó, L.A. Oro, in: Homogeneous Hydrogenation, Kluwer Academic Publishers, Dordrecht, 1994; (b) Handbook of Homogeneous Hydrogenation; J.G. de Vries, C.J. Elsevier (Eds.), WilleyVCH, Weinheim, 2007.

[19] (a) D.J. Law, R.G. Cavell, J. Mol. Catal. 91 (1994) 175-186; (b) R.G. Cavell, D.J. Law, R.W. Reed, US Pat. Appl. (1994) US887014.

[20] R. Venkateswaran, M.S. Balakrishna, S.M. Mobin, Eur. J. Inorg. Chem. (2007) 19301938.

[21] F. Lorenzini, K.T. Hindle, S.J. Craythorne, A.R. Crozier, F. Marchetti, C.J. Martin, P.C. Marr, A.C. Marr, Organometallics 25 (2006) 3912-3919.

[22] In general, involvement of chiral iminophosphoranes in asymmetric catalysis remains almost unexplored: (a) M.T. Reetz, E. Bohres, R. Goddard, Chem. Commun. (1998) 935-936; (b) M. Sauthier, J. Forniés-Cámer, L. Toupet, R. Réau, Organometallics 19 (2000) 553-562.

[23] Unexploited examples in catalysis of transition-metal complexes with optically active iminophosphorane-phosphine ligands can be found in: L. Boubekeur, L. Ricard, N. Mézailles, M. Demange, A. Auffrant, P. Le Floch, Organometallics 25 (2006) 30913094.

[24] (a) T.T. Co, S.C. Shim, C.S. Cho, T.-J. Kim, S.O. Kang, W.-S. Han, J. Ko, C.-K. Kim, Organometallics 24 (2005) 4824-4831; (b) T.T. Co, T.-J. Kim, Chem. Commun. (2006) 3537-3539; (c) T.-J. Kim, Y.M. Chang, G.H. Lee, I.K. Kang, T.T. Co, Repub. Korean Kongkae Taeho Kongbo (2007) KR2007013905.

[25] See, for example: (a) R.H. Morris, Chem. Soc. Rev. 38 (2009) 2282-2291 and references cited therein; (b) S. Fleisher, S. Zhou, K. Junge, M. Beller, Angew. Chem. Int. Ed. 52 (2013) 5120-5124 and references cited therein.

[26] A. Buchard, H. Heuclin, A. Auffrant, X.F. Le Goff, P. Le Floch, Dalton Trans. (2009) 1659-1667.

[27] See, for example: (a) G. Zassinovich, G. Mestroni, S. Gladiali, Chem. Rev. 92 (1992) 1051-1069; (b) S. Gladiali, E. Alberico, Chem. Soc. Rev. 35 (2006) 226-236; (c) J.S.M. Samec, J.-E. Bäckvall, P.G. Andersson, P. Brandt, Chem. Soc. Rev. 35 (2006) 237-248; (d) S. Gladiali, R Taras, in: Modern Reduction Methods, P.G. Andersson, I.J. Munslow 
(Eds.), Wiley-VCH, Weinheim, 2008, pp. 135-158; (e) M. Wills, in: Modern Reduction Methods, P.G. Andersson, I.J. Munslow (Eds.), Wiley-VCH, Weinheim, 2008, pp. 271296.

[28] A. Buchard, E. Payet, A. Auffrant, X. Le Goff, P. Le Floch, New J. Chem. 34 (2010) 2943-2949.

[29] V. Cadierno, P. Crochet, J. García-Álvarez, S.E. García-Garrido, J. Gimeno, J. Organomet. Chem. 663 (2002) 32-39.

[30] (a) V. Cadierno, J. Díez, S.E. García-Garrido, S. García-Granda, J. Gimeno, J. Chem. Soc., Dalton Trans. (2002) 1465-1472; (b) V. Cadierno, J. Díez, J. García-Álvarez, J. Gimeno, Chem. Commun. (2004) 1820-1821.

[31] (a) V. Cadierno, P. Crochet, J. Díez, J. García-Álvarez, S.E. García-Garrido, J. Gimeno, S. García-Granda, M.A. Rodríguez, Inorg. Chem. 42 (2003) 3293-3307; (b) V. Cadierno, P. Crochet, J. Díez, J. García-Álvarez, S.E. García-Garrido, S. GarcíaGranda, J. Gimeno, M.A. Rodríguez, Dalton Trans. (2003) 3240-3249.

[32] A. Picot, H. Dyer, A. Buchard, A. Auffrant, L. Vendier, P. Le Floch, S. Sabo-Etienne, Inorg. Chem. 49 (2010) 1310-1312.

[33] L. Boubekeur, S. Ulmer, L. Ricard, N. Mézailles, P. Le Floch, Organometallics 25 (2006) 315-317.

[34] H. Dyer, A. Picot, L. Vendier, A. Auffrant, P. Le Floch, S. Sabo-Etienne, Organometallics 30 (2011) 1478-1486.

[35] See, for example: (a) Cross-Coupling Reactions: A practical Guide, N. Miyaura (Ed.), Springer, Berlin, 2002; (b) Metal-Catalyzed Cross-Coupling Reacions ( $2^{\text {nd }}$ edition), A. de Meijere, F. Diederich (Eds.), Wiley-VCH, Weinheim, 2004; (c) Applied CrossCoupling Reactions, Y. Nishihara (Ed.), Springer, Berlin, 2013.

[36] (a) K. Sonogashira, Y. Tohda, N. Hagihara, Tetrahedron Lett. 16 (1975) 4467-4470; (b) K. Sonogashira, J. Organomet. Chem. 653 (2002) 46-49; (c) R. Chinchilla, C. Nájera, Chem. Rev. 107 (2007) 874-922; (d) R. Chinchilla, C. Nájera, Chem. Soc. Rev. 40 (2011) 5048-5121.

[37] A. Arques, D. Auñon, P. Molina, Tetrahedron Lett. 45 (2004) 4337-4340.

[38] P. Molina, A. Arques, A. García, M.C. Ramírez de Arellano, Tetrahedron Lett. 38 (1997) 7613-7616.

[39] (a) N. Miyaura, K. Yamada, A. Suzuki, Tetrahedron Lett. 20 (1979) 3437-3440; (b) N. Miyaura, A. Suzuki, Chem. Commun. (1979) 866-867; (c) N. Miyaura, A. Suzuki, Chem. Rev. 95 (1995) 2457-2483; (d) A. Suzuki, J. Organomet. Chem. 576 (1999) 
147-168; (e) A. Suzuki, Chem. Commun. (2005) 4759-4763; (e) F. Alonso, I.P. Beletskaya, M. Yus, Tetrahedron 64 (2008) 3047-3101; (f) R. Narayanan, Molecules 15 (2010) 2124-2138.

[40] A. Buchard, B. Komly, A. Auffrant, X.F. Le Goff, P. Le Floch, Organometallics 27 (2008) 4380-4385.

[41] Boronic Acids: Preparation and Applications in Organic Synthesis, Medicine and Materials ( $2^{\text {nd }}$ edition), D.G. Hall (Ed.), Wiley-VCH, Weinheim, 2011.

[42] (a) K. Tamao, K. Sumitani, M. Kumada, J. Am. Chem. Soc. 94 (1972) 4374-4376; (b) R.J.P. Corriu, J.P. Masse, J. Chem. Soc., Chem. Commun. (1972) 144; (c) K. Tamao, J. Organomet. Chem. 653 (2002) 23-26; (d) J. Adrio, J.C. Carretero, ChemCatChem 2 (2010) 1384-1386; (e) M.M. Heravi, P. Hajiabbasi, Monatsh. Chem. 143 (2012) 15751592.

[43] Z.-X. Wang, L. Wang, Chem. Commun. (2007) 2423-2425.

[44] K. Sun, L. Wang, Z.-X. Wang, Organometallics 27 (2008) 5649-5656.

[45] C. Zhang, Z.-X. Wang, Organometallics 28 (2009) 6507-6514.

[46] (a) A.O. King, N. Okukado, E. Negishi, J. Chem. Soc., Chem. Commun. (1977) 683684; (b) E. Negishi, A.O. King, N. Okukado, J. Org. Chem. 42 (1977) 1821-1823; (c) P. Knochel, R.D. Singer, Chem. Rev. 93 (1993) 2117-2188; (d) V.P. Phapale, D.J. Cárdenas, Chem. Soc. Rev. 38 (2009) 1598-1607; (e) C. Valente, M.E. Belowich, N. Hadei, M.G. Organ, Eur. J. Org. Chem. (2010) 4343-4354; (f) L. Jin, A. Lei, Org. Biomol. Chem. 10 (2012) 6817-6825.

[47] See, for example: (a) J. Skupińska, Chem. Rev. 91 (1991) 613-648; (b) J.T. Dixon, M.J. Green, F.M. Hess, D.H.Morgan, J. Organomet. Chem. 689 (2004) 3641-3668; (c) F. Speiser, P. Braunstein, L. Saussine, Acc. Chem. Res. 38 (2005) 784-793; (d) D.F. Wass, Dalton Trans. (2007) 816-819; (e) G. Fink, H.-H. Brintzinger, in: Metal Catalysis in Industrial Organic Processes, G.P. Chiusoli, P.M. Maitlis (Eds.), RSC Publishing, Cambridge, 2008, pp. 218-254; (f) D.S. McGuinness, Chem. Rev. 111 (2011) 2321-2341.

[48] (a) W. Keim, F.H. Kowaldt, R. Goddard, C. Krüger, Angew. Chem. Int. Ed. Engl. 17 (1978) 466-467; (b) B. Reuben, H. Wittcoff, J. Chem. Ed. 65 (1988) 605-607; (c) P. Kuhn, D. Sémeril, D. Matt, M.J. Chetcuti, P. Lutz, Dalton Trans. (2007) 515-528.

[49] In the context of a broad study Cavell and co-workers described the use of several transition metal iminophosphorane-based complexes, including $\left[\mathrm{Ni}\left\{\kappa^{2}-(P, N)\right.\right.$ $\left.\left.\mathrm{Ph}_{2} \mathrm{PCH}_{2} \mathrm{P}\left(=\mathrm{N}-p-\mathrm{C}_{6} \mathrm{~F}_{4} \mathrm{CN}\right) \mathrm{Ph}_{2}\right\}_{2}\right] \quad$ and $\quad\left[\mathrm{Ni}(\operatorname{cod})\left\{\kappa^{2}-(P, N)-\mathrm{Ph}_{2} \mathrm{PCH}_{2} \mathrm{P}(=\mathrm{N}-p-\right.\right.$ 
$\left.\left.\mathrm{C}_{6} \mathrm{~F}_{4} \mathrm{CN}\right) \mathrm{Ph}_{2}\right\}$ ], for the polymerization of ethylene. Unfortunately, these iminophosphorane-phosphine $\mathrm{Ni}(0)$ complexes were no viable catalysts due their poor solubility in conventional organic solvents: (a) A.F. Somogyvari, B.L. Creed, A.P. Nicola, A.R. Sanger, D.J. Law, R.G. Cavell, US Pat. Appl. (1996) US5557023; (b) R.G. Cavell, B. Creed, L. Gelmini, D.J. Law, R. McDonald, A.R. Sanger, A. Somogyvari, Inorg. Chem. 37 (1998) 757-763; (c) I. McKay, A. Ciupa, A.F. Somogyvari, B.L. Creed, A.R. Sanger, D.J. Law, R.G. Cavell, US Pat. Appl. (2000) US6013745.

[50] C. Zhang, W.-H. Sun, Z.-X. Wang, Eur. J. Inorg. Chem. (2006) 4895-4902.

[51] (a) A. Buchard, A. Auffrant, C. Klemps, L. Vu-Do, L. Boubekeur, X.F. Le Goff, P. Le Floch, Chem. Commun. (2007) 1502-1504; (b) V. Tognetti, A. Buchard, A. Auffrant, I. Ciofini, P. Le Floch, C. Adamo, J. Mol. Model. 19 (2013) 2107-2118.

[52] See, for example: (a) D. Rechavi, M. Lemaire, Chem. Rev. 102 (2002) 3467-3494; (b) H. Lebel, J.-F. Marcoux, C. Molinaro, A.B. Charette, Chem. Rev. 103 (2003) 9771050; (c) R.A.C. Leao, V.F. Ferreira, S. Pinheiro, Quim. Nova 30 (2007) 1721-1731; (d) H. Pellissier, Tetrahedron 64 (2008) 7041-7095.

[53] V.D.M. Hoang, P.A.N. Reddy, T.-J. Kim, Tetrahedron Lett. 48 (2007) 8014-8017.

[54] See, for example: (a) X.L. Hou, H.Y. Cheung, T.Y. Hon, P.L. Kwan, T.H. Lo, S.Y. Tong, H.N.C. Wong, Tetrahedron 54 (1998) 1955-2020; (b) R.C.D. Brown, Angew. Chem. Int. Ed. 44 (2005) 850-852; (c) S.F. Kirsch, Org. Biomol. Chem. 4 (2006) 20762080; (d) D.M. D’Souza, T.J.J. Müller, Chem. Soc. Rev. 36 (2007) 1095-1108; (e) N.T. Patil, Y. Yamamoto, ARKIVOC 10 (2007) 121-141; (f) G. Balme, D. Bouyssi, N. Monteiro, Heterocycles 73 (2007) 87-124; (g) V. Cadierno, P. Crochet, Curr. Org. Synth. 5 (2008) 343-364; (h) L. Hao, Z.-P. Zhan, Curr. Org. Chem. 15 (2011) 16251643; (i) W.J. Moran, A. Rodríguez, Org. Prep. Proced. Int. 44 (2012) 103-130; (j) W. Jia-Jie, Y. Zhu, Z.-P. Zhan, Asian J. Org. Chem. 1 (2012) 108-129.

[55] V. Cadierno, J. Díez, J. García-Álvarez, J. Gimeno, N. Nebra, J. Rubio-García, Dalton Trans. (2006) 5593-5604.

[56] B. Gabriele, G. Salerno, M. Costa, Synlett (2004) 2468-2483 and references cited therein.

[57] See, for example: (a) S. Swaminathan, K.V. Narayanan, Chem. Rev. 71 (1971) 429438; (b) D.A. Engel, G.B. Dudley, Org. Biomol. Chem. 7 (2009) 4149-4158; (c) V. Cadierno, P. Crochet, S.E. García-Garrido, J. Gimeno, Dalton Trans. 39 (2010) 4015- 
4031; (d) J. García-Álvarez, S.E. García-Garrido, P. Crochet, V. Cadierno, Curr. Top. Catal. 10 (2012) 35-56.

[58] (a) J. García-Álvarez, J. Díez, J. Gimeno, C.M. Seifried, Chem. Commun. 47 (2011) 6470-6472; (b) J. García-Álvarez, J. Díez, J. Gimeno, C.M. Seifried, C. Vidal, Inorg. Chem. 52 (2013) 5428-5437.

[59] Detailed information regarding ruthenium Lewis acid catalyzed Diels-Alder reactions can be found in the following review articles: (a) R.F.R. Jazzar, E.P. Kündig, in: Ruthenium in Organic Synthesis, S.-I. Murahashi (Ed.), Wiley-VCH, Weinheim, 2004, pp. 257-276; (b) S. Dérien, F. Monnier, P.H. Dixneuf, Top. Organomet. Chem. 11 (2004) 1-44; (c) J. Faller, J. Parr, Curr. Org. Chem. 10 (2006) 151-163.

[60] A.E. Díaz-Álvarez, P. Crochet, M. Zablocka, V. Cadierno, C. Duhayon, J. Gimeno, J.P. Majoral, New J. Chem. 30 (2006) 1295-1306.

[61] (a) M.S. Karasch, G. Sosnovsky, J. Am. Chem. Soc. 80 (1958) 756-756; (b) M.S. Karasch, G. Sosnovsky, N.C. Yang, J. Am. Chem. Soc. 81 (1959) 5819-5824.

[62] V.D.M. Hoang, P.A.N. Reddy, T.-J. Kim, Organometallics 27 (2008) 1026-1027.

[63] (a) J. Eames, M. Watkinson, Angew. Chem. Int. Ed. 40 (2001) 3567-3571; (b) R.M. Camble, G. Sekar, M. Chandrasekhar, V.K. Singh, PINSA-A: Proc. Indian Natl. Sci. Acad., Part A 68 (2002) 423-433; (c) M.B. Andrus, J.C. Lashley, Tetrahedron 58 (2002) 845-866; (d) I.I. Moiseev, M.N. Vargaftik, Coord. Chem. Rev. 248 (2004) 2381-2391.

[64] T.T. Co, S.C. Shim, C.S. Cho, D.-U. Kim, T.-J. Kim, Bull. Korean Chem. Soc. 26 (2005) 1359-1365.

[65] R.G. Cavell, K.V. Katti, PCT Int. Appl. (1992) WO92/04118. 


\title{
Iminophosphorane-phosphines: Versatile ligands for homogeneous catalysis
}

\author{
Joaquín García-Álvarez, Sergio E. García-Garrido and Victorio Cadierno*
}

In this review article, a comprehensive account of the applications of transition-metal complexes containing functionalized ligands featuring both an iminophosphorane and a phosphine moiety in homogeneous catalysis is presented. Among others, metal-catalyzed hydrogenation and transfer hydrogenation reactions, C-C cross-couplings, olefin oligomerization and cyclopropanation processes, allylic alkylation and oxidation reactions, Meyer-Schuster rearrangements and cycloisomerization processes are discussed.

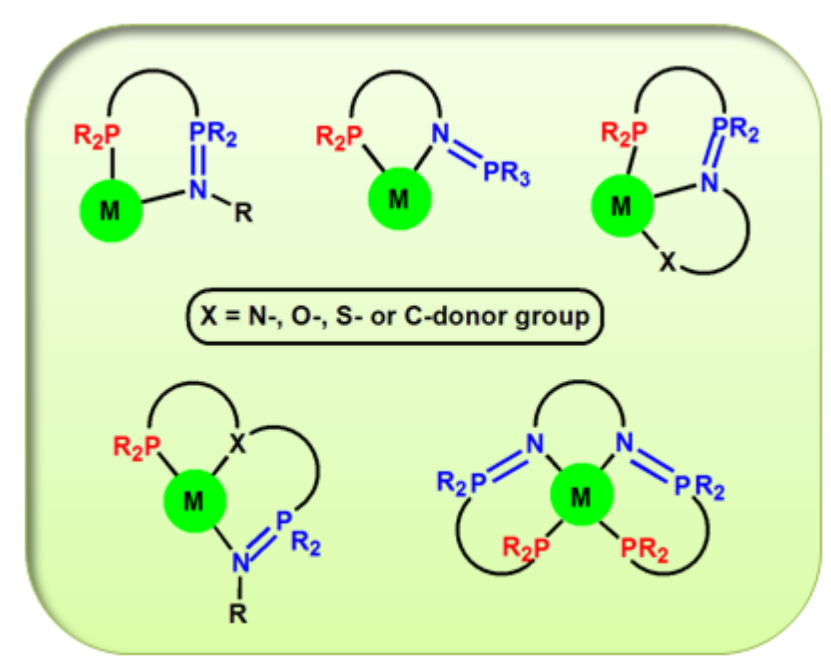




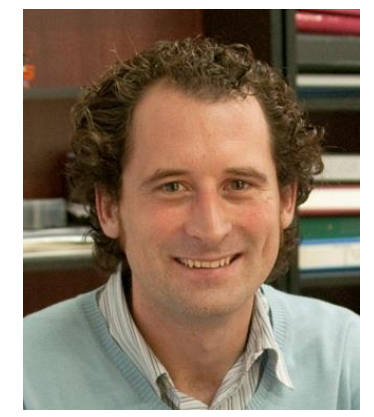

Joaquín García-Álvarez received his $\mathrm{PhD}$ degree from the University of Oviedo (Spain) in 2005 under the supervision of Prof. J. Gimeno and Dr. V. Cadierno. He then joined the group of Prof. R. E. Mulvey at the University of Strathclyde in Glasgow (Scotland) for a two-years and a half postdoctoral stay. He returned to the University of Oviedo in 2008 where he is currently a "Ramón y Cajal" postdoctoral researcher.

The current focus of his research is the chemistry of transition metal complexes containing iminophosphorane ligands and their applications in homogeneous catalysis.

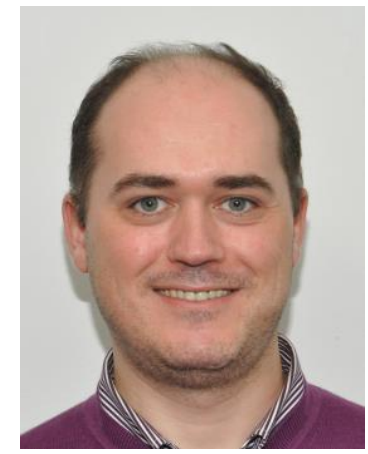

Sergio E. García-Garrido received his $\mathrm{PhD}$ degree from the University of Oviedo (Spain) in 2005 under the supervision of Prof. J. Gimeno and Dr. V. Cadierno. After a postdoctoral stay (2005-2007) at the School of Chemistry of Southampton University (UK), working under the supervision of Prof. P. A. Gale, he returned to the University of Oviedo where he is currently a "Ramón y Cajal" postdoctoral researcher. His current lines of work focus on the chemistry of organometallic complexes and the development of new supramolecular structures as well as on their applications in homogeneous and heterogeneous catalysis.

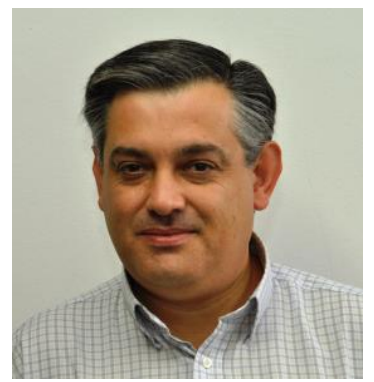

Victorio Cadierno received his $\mathrm{PhD}$ degree from the University of Oviedo (Spain) in 1996 under the supervision of Prof. J. Gimeno. He then joined the group of Dr. J. P. Majoral at the Laboratoire de Chimie de Coordination (LCC-CNRS) in Toulouse (France) for a two-years postdoctoral stay. Thereafter, he returned to the University of Oviedo where he is currently Associate Professor of Inorganic Chemistry. His research involves the use of transition metal complexes for catalytic organic synthesis, with special focus in ruthenium chemistry. 